\title{
NUEVOS DATOS PARA EL ESTUDIO DE LOS MÚSICOS NEBRA EN ARAGÓN ${ }^{1}$
}

\author{
Antonio EZQuerro Esteban \\ Departamento de Musicología, CSIC
}

\begin{abstract}
On the occasion of the third centenary of the birth of the composer José Nebra in the town of Calatayud in the Province of Aragon, this article provides further information concerning the prevalence of a number of musicians bearing that same surname, both in Calatayud and in the city of Zaragoza. If, previously, certain things were only known through indirect references, now, for the first time, we can present photographs of the marriage certificate that initiated that family saga, together with the baptismal certificates of his brothers (José Bernardo, José Melchor, Francisco Javier and Joaquín). We are including for the first time José Nebra's certificate of confirmation (possibly, José Melchor), newly acquired information establishing the relationship between the Nebra and Blasco families (the latter family tree originating in Sevilla), as well as information from the principal music archives in Aragón, located in the Cathedrals in the city of Zaragoza, concerning the activities of the Nebra family and containing their public exam papers and surviving compositions.
\end{abstract}

\section{Resumen}

Con ocasión del tercer centenario del nacimiento del compositor José Nebra en la localidad aragonesa de Calatayud, el presente artículo ofrece nuevas informaciones sobre la presencia de los diversos músicos así apellidados, tanto en Calatayud como en Zaragoza. A pesar de que algunos datos ya fueran conocidos por referencias indirectas, se aportan ahora por vez primera, las imágenes gráficas de la partida matrimonial del iniciador de la saga familiar, así como las partidas de bautismo de los hermanos (José Bernardo, José Melchor, Francisco Javier y Joaquín). Se incluye asimismo por vez primera la partida de confirmación de José Nebra (posiblemente, José Melchor), nuevos datos para establecer las conexiones entre los Nebra y los Blasco (rama familiar esta última que se desarrollaría en Sevilla), e informaciones procedentes del principal archivo musical aragonés, el de las catedrales de Zaragoza, con noticia de las actividades de los Nebra ahí desarrolladas, ejercicios de oposiciones y composiciones conservadas.

\section{Presupuestos}

Se cumple este año el tercer centenario del nacimiento de un músico español extraordinario, natural de Calatayud (Zaragoza): el compositor José Nebra, que fuera sucesivamente organista del convento de las Descalzas Reales de Madrid, músico de cámara de los duques de Osuna

1. El presente trabajo se inserta en el marco del Proyecto de Investigación del Plan Nacional (programa de Promoción General del Conocimiento), titulado La circulación de la música y los músicos en la antigua Corona de Aragón, 1600 1850 (PB98-0477), del que el autor de este artículo es investigador principal. 
—donde coincidió con Antonio Literes-y, sobre todo, primer organista, vicemaestro de capilla y vicerrector del colegio de niños cantorcicos de la Real Capilla española (bajo los monarcas Luis I, el segundo reinado de Felipe v, Fernando vi y Carlos III), además de maestro de clave del infante don Gabriel, y maestro de composición de José Lidón, de su propio sobrino Manuel Blasco de Nebra, y del célebre padre Antonio Soler, a quien prologó su tratado teórico musical Llave de la modulación (1761).

Sobre la personalidad de José Nebra, la relevancia del papel que desempeñó en el panorama musical hispánico de la época (no sólo en el ámbito de la corte ${ }^{2}$ y los teatros - donde coincidió con D. Scarlatti, J. Facco o F. Falconi, y colaboró con dramaturgos como A. Cañizares-, sino también en la música religiosa y la tratadística), y la gran calidad de sus composiciones, se ha escrito mucho, particularmente en los últimos años, con la consiguiente considerable ampliación y mejora de los conocimientos actuales acerca de dicho músico, y de sus actividades y repercusión ${ }^{3}$.

Pero el florecimiento de su ingenio ha de enmarcarse necesariamente, no tan sólo en el contexto de su actividad personal en el entorno madrileño, que sin duda fue el fundamental y determinante, sino también, en primer lugar, en el de su formación musical inicial -y sus contactos, seguramente constantes- en el seno de una familia de músicos - padre, hermanos, primos, sobrinos...-, hasta la fecha todavía escasamente conocidos. De ellos, sólo a modo de ejemplo, podemos destacar su afán por conocer la mejor música del momento (que llevó a su hermano Francisco Javier a procurarse en Roma una esmeradísima copia en el año 1727 con las suites para clave de Georg Friedrich Händel, la cual actualmente se conserva en el archivo catedralicio zaragozano), o su presencia continuada en puestos musicales de importancia (su hermano Joaquín fue organista primero de la Catedral Metropolitana del Salvador de Zaragoza — cabeza, en lo eclesiástico, de la Corona de Aragón-durante más de medio siglo).

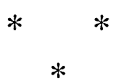

\section{En Calatayud}

En diversas ocasiones, se ha tratado de la procedencia aragonesa de la familia de los varios y afamados músicos apellidados Nebra, naturales varios de ellos de la capital del Jalón, Calatayud.

2. A propósito de la estancia de José de Nebra como organista del convento de las Descalzas Reales de Madrid, véanse algunas referencias en: -Paulino CAPDEPón VERDú: La Música en el Monasterio de las Descalzas Reales (siglo XVIII). Madrid, Alpuerto, Patrimonio Musical Español, 1999. Y sobre su producción conservada en el Palacio de Oriente, vid.: -José Peris Lacasa: Catálogo del Archivo de Música del Palacio Real de Madrid. Madrid, Patrimonio Nacional, 1993, pp. 399428 e íncipits musicales en pp. 65-69.

3. Véase bibliografía actualizada en los siguientes dos trabajos: -Ma Salud Álvarez Martínez: "Nebra. 1. Nebra Mezquita, José Antonio de. 2. Nebra Blasco, Francisco Javier de. 3. Nebra Blasco, José de. 4. Nebra Blasco, Joaquín Ignacio de", en Diccionario de la Música Española e Hispanoamericana. Vol. 7. Madrid, SGAE, 2000, pp. 1002-1009. Y muy especialmente: -Luis Antonio González MARín: José de Nebra (Calatayud, 1702 - Madrid, 1768). Un aragonés en la Real Capilla. Zaragoza, Institución «Fernando el Católico», 2002. 


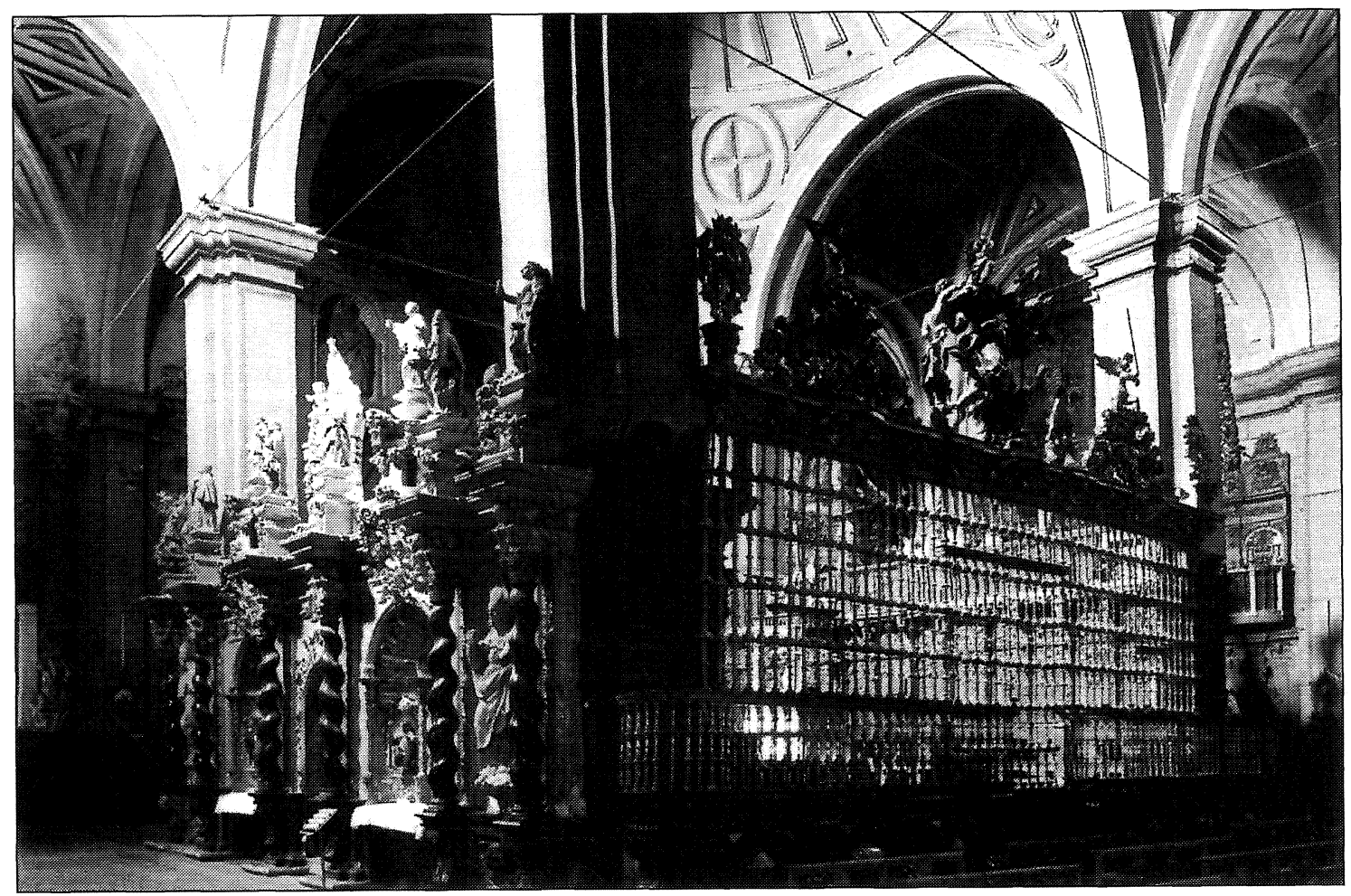

Figura 1

Colegiata de Santa María de Calatayud (Detalle del coro)

La vieja bibliografía existente - debida en su mayor parte al documentado trabajo que hiciera en su día Dionisio Preciado - aporta la transcripción de algunas partidas de bautismo y otros datos concretos ${ }^{4}$, que han mejorado ostensiblemente en los últimos años a raíz de los estudios posteriores de $\mathrm{M}^{\mathrm{a}}$ Salud Álvarez ${ }^{5}$. Pero sobre el aspecto particular y concreto del origen bil-

4. -Dionisio Preciado Ruiz de Alegría: "Joaquín Nebra (1709-1782). 52 largos años de organista en La Seo de Zaragoza (1730-1782). i y ı", en Tesoro Sacro Musical, No639 (Enero-Marzo 1977), pp. 12-17 y 40-45. -Miguel MarTíNEZ Millán: "Los Nebra en la Catedral de Cuenca (1711-1748)". en I Congreso Nacional de Musicología. Zaragoza. Sociedad Española de Musicología, Institución «Fernando el Católico», 1981, pp. 331-344. -Dionisio PrEClado RUIZ DE Alegría: Doce Compositores Aragoneses de Tecla (s. xVIII). Madrid, Editora Nacional, 1983, pp. 37-41. Este último trabajo repite prácticamente lo ya apuntado en el precedente trabajo a cargo del mismo autor, que - tras H. Eslava-, tuvo el mérito de ser el primero en llamar la atención sobre la familia Nebra al completo, y de preocuparse por documentarla adecuadamente. [Nada se dice a propósito de los Nebra y su actividad bilbilitana, por ejemplo, en el primer trabajo que se dedicó a la música en la principal iglesia de la ciudad: -Antonio Gallego: "Datos sobre la música en la Colegial de Calatayud (ss. XVIII-XIX)", en Tesoro Sacro Musical, Año 61, Nº 644 (Abril-Junio 1978), pp. 45-52]. Sobre la presencia en Cuenca de la familia Nebra, véase: -Miguel Martínez Millán: Historia musical de la Catedral de Cuenca. Cuenca, Diputación Provincial, 1988.

5. - Ma Salud Álvarez Martínez: El compositor José de Nebra. Tesis doctoral. Sevilla, Universidad, microfichas, 1992. 
bilitano de la familia no se han ofrecido especialmente nuevas luces, o datos que no fueran ya conocidos con anterioridad ${ }^{6}$.

Sobre el período del siglo XVIII en el que la familia Nebra estuvo relacionada con Calatayud, no se han conservado las actas capitulares ni otro tipo de documentación alusiva específicamente a la capilla de música de la principal iglesia de la ciudad, la Colegiata Mayor de Santa María ${ }^{7}$. Tampoco se ha conservado música de dicho período en la iglesia, debido a las diversas desamortizaciones de bienes eclesiásticos durante el siglo XIX, que afectaron plenamente a los fondos documentales de este templo.

Sea como fuere, es sabido que en el siglo XVIII desarrollaron sus actividades los músicos de la familia Nebra. Situaremos la cuestión. El conjunto de músicos apellidados Nebra se inicia con el padre, el aragonés José Antonio $\mathbf{N e b r a}^{8}$ —éste todavía a finales del siglo XVII, de quien se dice tradicionalmente que fuera organista en Santa María de Calatayud desde 1697-, para seguir con sus hijos, todos ellos naturales de Calatayud, José [Melchor] Nebra ${ }^{9}$, Francisco Javier

6. -Ma Salud Álvarez Martínez: José de Nebra Blasco. Vida y obra. Zaragoza, Institución «Fernando el Católico», 1993 [cfr. pp. 13-15]. -Francisco José SENRA LAZO: “Apuntes biográficos de Manuel Blasco de Nebra-Los Nebra-José Blasco de Nebra-Manuel Blasco de Nebra-El expediente de Corona y primeros grados-Los últimos años-Un legado sin paradero conocido", en Manuel Blasco de Nebra. Sonatas para pianoforte. Sevilla, 1993. [Comentarios al cuadernillo del CD interpretado por Tony Millán, Almaviva Ds 0108 DDD]. Este trabajo, es tal vez el que más luces aporta al respecto, transmitiendo documentación de primera mano relativa fundamentalmente a la rama sevillana de la familia Nebra, apellidada Blasco. - $\mathrm{M}^{\mathrm{a}}$ Salud Álvarez MARTínez: Obras inéditas para tecla y Cuatro villancicos y una cantada. Zaragoza, Institución «Fernando el Católico», 1995.

7. Sobre la documentación conservada, así como la historia musical de la colegiata de Santa María, véase: -Antonio EzQuerro Esteban: "Calatayud, Archivo musicales de", en Gran Enciclopedia Aragonesa. Apéndice III. Zaragoza, Aragonali, 1997, pp. 69-72. -Antonio EzQuerro Esteban; y Ma Cinta Guerrero Segarra: "La música en la Real Colegiata del Santo Sepulcro de Calatayud", en Revista de Musicología, xxı/2 (1999), p. 17. (Agradezco las facilidades dadas para la realización de este trabajo por el Abad de la colegial de Santa María, D. Félix Uriel Miñana).

8. José [Antonio] Nebra Mezquita ( ${ }^{*} \mathrm{La}$ Hoz de la Vieja — provincia de Teruel, arzobispado de Zaragoza-, bautizado el 23-XI-1672; †Cuenca, 4-XII-1748). Hijo de José Nebra y Josefa Mezquita. (De la localidad de La Hoz, procedería también años después, la familia de los afamados organistas apellidados Moreno y Polo, todos ellos formados musicalmente como infantes de coro en La Seo de Zaragoza). [Vid. -Dionisio Preciado Ruiz de Alegría: Doce Compositores Aragoneses..., op. cit., 1983, p. 27]. Fue, casi con certeza, organista en la Colegiata de Santa María de Calatayud (la documentación de la iglesia correspondiente a estos años no se ha conservado), donde lo encontraríamos ya en 1697, y donde residiría al menos hasta 1709 (y posiblemente hasta 1711). Allí se casó (con Rosa Blasco Bian) y nacieron sus cuatro primeros hijos, de quienes trataremos más adelante. En 1709 aparece por última vez documentado en Calatayud. En 1711 pasó como Organista a la Catedral de Cuenca, donde consta que era también buen arpista, además de un compositor capaz. Si bien pudo continuar en Calatayud, entre 1709 (cuando nace su hijo Joaquín) y 1711, desaparece de la documentación bilbilitana. Ya organista en Cuenca, en 1729, permutó su puesto por el magisterio de capilla en esa misma ciudad castellana, donde fallecería tras treinta y siete años de servicio a su catedral. Su partida de bautismo, así como el nombre de su hermana, «Josefa Nebra», nacida el 20-11-1676, se conoce desde hace algún tiempo. En la ciudad castellana tendría todavía otros dos hijos, Gabriel, que posiblemente falleció muy joven, y María Ana. [Vid. -Dionisio Preciado Ruiz de Alegría: "Joaquín Nebra (1709-1782). 52 años largos...", op. cit., (1977), p. 16].

9. José [Melchor Baltasar Gaspar] Nebra Blasco (*Calatayud -Zaragoza-, bautizado el 6-I-1702; †Madrid, 11-VII-1768). El más famoso de todos, compositor que triunfó en la Capilla Real de Madrid como organista primero, desde 1724 hasta su muerte. Fue también asistente y amigo del maestro Francisco Corselli (o Courcelle), entre otras muchas facetas que desarrolló en su dilatada carrera profesional. Sobre este compositor, vid. -Nicolás ÁlvarEz SOlar-QuiNTES: "El compositor Francisco Courcelle", en Anuario Musical, vı (1951), pp. 180-204. -ID.: "El compositor español José de Nebra (11-VII-1768). Nuevas aportaciones para su biografía", en Anuario Musical, ix (1954). -Ma Salud Alvarez MarTínez: "José de Nebra a la luz de las últimas investigaciones", en Anuario Musical, 47 (1992), pp. 153-173. -ID.: José de Nebra Blasco. Vida..., op. cit., 1993. -José Máximo LeZA Cruz: "Nebra Blasco, José Melchor Baltasar Gaspar”, en Gran Enciclopedia Aragonesa. Apéndice III. Zaragoza, Aragonali, 1997, pp. 296-297. -ID.: "Nebra", en The New Grove Dictionary of Music and Musicians. $2^{\mathrm{a}}$ edición. Londres, Macmillan, 2000. Y muy en especial, cfr. el trabajo más reciente, y a mi juicio el más notorio e interesante por el punto de vista y planteamientos escogidos, además de por lo documentado: -Luis Antonio GonZÁlez Marín: José de Nebra (Calatayud, 1702 - Madrid, 1768). Un aragonés..., op. cit., 2002. 
Nebra ${ }^{10}$ y Joaquín Nebra ${ }^{11}$, cuyas partidas de nacimiento constan entre la documentación de la Ilustre y Real Colegiata de Santa María (Quinque libris; Bautismos). Algunas noticias sobre ellos referidas a Calatayud fueron ya transcritas por Dionisio Preciado, cuyos datos han ido pasando sin embargo con posterioridad de mano en mano sin, al parecer, ampliar las informaciones ni siquiera cotejar los originales bilbilitanos ${ }^{12}$.

10. Francisco Javier [Ignacio Benito] Nebra Blasco (*Calatayud -Zaragoza-, bautizado el 16-IV-1705; † Cuenca, 4-vil-1741). Muy posiblemente, recibiera sus primeras nociones de música de manos de su propio padre en Calatayud, donde residiría hasta 1711, para formarse poco más tarde, ya en la Catedral de Cuenca, como infante de coro en el Colegio de San Pedro de la mencionada seo castellana. Sustituyó a Miguel Soriano como Organista primero de La Seo de Zaragoza el 14-viII-1727, cargo que ocupó hasta 1729, fecha en que pasó nuevamente como Organista a la Catedral de Cuenca, al pasar su padre a maestro de capilla en dicha ciudad. De su estancia en Zaragoza sabemos de su actuación al frente de la capilla de música de La Seo el 1-III-1729, con ocasión del estreno de una «especiosa festiva aclamación de música en forma de ópera» de su composición, a la que asistieron la nobleza local y los militares de guarnición en la ciudad, celebración escénica de la que daba noticia la Gaceta de Zaragoza. Esta obra, respondía a un encargo del capitán general de Zaragoza, Luis de Espínola (o Lucas de Espinosa, según otras fuentes), con vistas a celebrar, en su casa, la onomástica del rey Felipe v. Ya en Cuenca, lugar en donde se conservan la mayor parte de sus obras, desempeñó su cargo al frente del órgano catedralicio, desde el 4-XI-1729 hasta su muerte, acaecida a los 36 años, incluso algunos años antes que la de su propio padre, con quien habría compartido durante largo tiempo las principales responsabilidades musicales del templo conquense. En dicha ciudad castellana, había contraído matrimonio con Juana Vieco. [Sobre la ópera mencionada, véanse los datos erróneos aportados por A. Lozano - quien señala al militar citado como Lucas Espinosa-, los cuales ya fueron en su día refutados por D. Preciado (en Tesoro Sacro Musical..., 1977), en: -Antonio EzQuerro Esteban, ed.: Antonio Lozano González: «La Música Popular, Religiosa y Dramática en Zaragoza, desde el siglo XVI hasta nuestros días» (Zaragoza, 1895). $3^{\text {a }}$ edición. Zaragoza, Gobierno de Aragón-Diputación de Zaragoza-Ayuntamiento de Zaragoza, 1994, pp. 52 [172] y 113 [233]. Por su parte, sobre la estancia de Francisco Javier en Cuenca y la de su padre, vid.: -Miguel Querol Gavaldé: Cantatas y canciones para voz solista e instrumentos (1640-1760). Barcelona, CSIC, «Monumentos de la Música Española, XXXV», «Música Barroca Española, vol. V», 1973, p. 12. (Se transcribe ahí además una «Partita amorosa» de este compositor, titulada Descuidado el ruyseñor, para Tiple, dos violines y acompañamiento). -Miguel MARTínez MiLlán: "Los Nebra en la Catedral de Cuenca (1711-1748)", en I Congreso Nacional de Musicología. Zaragoza, Sociedad Española de Musicología, Institución «Fernando el Católico», 1981, pp. 331-344. Y también: -ID.: Historia Musical de la Catedral de Cuenca..., op. cit., 1988].

11. Joaquín [Ignacio] Nebra Blasco (*Calatayud - Zaragoza-, bautizado el 25-v-1709; † Zaragoza, 16-VIII1782). Trasladado sin duda con su familia a Cuenca en 1711 , allí habría recibido sus primeras nociones musicales. En 1730 pidió la plaza de Organista de La Seo de Zaragoza, vacante al dejarla su hermano Francisco Javier para pasar a igual cargo en Cuenca. Opositó junto a otros muchos contendientes y, a pesar de su juventud y de no haber obtenido el primer puesto en los ejercicios, obtuvo la organistía zaragozana. (Puede verse el desarrollo pormenorizado de parte de los ejercicios de oposición en: -Dionisio Preciado Ruiz de Alegría: Doce Compositores..., op. cit., 1983, pp. 47-48; y también en el presente artículo). Ocupó, pues, la plaza de Organista de La Seo de Zaragoza, durante 52 años, desde el 11-III-1730, hasta su muerte. Se casó con María Redonet Aino. [Repárese en que, precisamente, en 1692, un músico llamado Joaquín Redonet —acaso familiar de la esposa de Joaquín Nebra-, había actuado como organista segundo de La Seo y ayudante de Andrés de Sola]. Además de las dos piezas suyas que hoy se dan a conocer aquí (una Paso y un Verso sobre el Veni creator), conservadas en el archivo catedralicio de Zaragoza, compuso el oratorio La caridad más perfecta, para las fiestas de canonización de San Camilo de Lelis (folleto con el texto impreso, Zaragoza, Imprenta del Rey, 1746?), que se cantó en Zaragoza, en la casa de San Valero y San Vicente, y cuyos personajes eran: Cristo, San Camilo, la Caridad, la Constancia, y el coro. (Cfr.: -Antonio Ezquerro Esteban, ed.: Antonio Lozano González: «La Música..., op. cit., 1994, pp. 112-113 [232-233]). Joaquín Nebra escribió además algunas piezas litúrgicas que se conservan en la Catedral de Cuenca (una Salve y una Lamentación $3^{a}$ del Viernes Santo), una colección o Juego de versos para órgano (cuarenta versos a dos voces, en la colección privada - fols. 29 a 46- de la organista Presentación Ríos), una Pastorela en octavo tono que se conserva en el archivo de Salvatierra (Álava) y un par de Sonatas a él atribuidas (una de ellas, para clarines, en quinto tono punto alto), a pesar de que indican escuetamente ser de «Nebra» (en el archivo de Valderrobres - Teruel-). Sobre la personalidad y producción de Joaquín Nebra, cfr.: -Dionisio Preciado Ruiz DE Alegría: "Joaquín Nebra (1709-1782). 52 años largos...", op. cit., 1977, pp. 1217. [Preciado cita aquí a un prácticamente desconocido sobrino de Joaquín - hijo de un hermano (¿de Francisco Javier?)residente en Madrid, Ilamado «Miguel Nebra», así como a una sobrina monja - iIgnacia?, hija de Francisco Javier-, residente en Cuenca]. -ID.: "Joaquín Nebra (1709-1782). 52 años largos...", op. cit., 1977, pp. 40-45. -ID.: Doce Compositores..., op. cit., 1983, pp. 35-41. -José Vicente GonzÁlez VAlle: Siete Palabras de Cristo en la Cruz. Barcelona, CSIC, «Monumentos de la Música Española LXI», 2000, pp. 17-72. -ID.: Vaciados de los libros de fábrica de La Seo y El Pilar de Zaragoza (inéditos).

12. -Dionisio Preciado Ruiz de Alegría: "Joaquín Nebra (1709-1782). 52 años...,, op. cit., 1977, pp. 12-17. 
En realidad, las noticias se reducen casi siempre, en la mayor parte de la bibliografía disponible al respecto, a los «cuatro Nebras» que ya citara H. Eslava, como el Nebra de Cuenca, el de Zaragoza, el de Madrid, y el de Sevilla (este úlltimo, no «Nebra», sino «Blasco») ${ }^{13}$. José V. González Valle apunta también algunos datos sobre estos músicos en cuanto a sus relaciones con las catedrales zaragozanas ${ }^{14}$. Por su parte, Dionisio Preciado parece dilucidar a quién corresponde cada una de las identificaciones geográficas apuntadas por Eslava, añadiendo además un quinto Nebra, padre de la dinastía ${ }^{15}$. Su aportación en este sentido, aunque ciertamente amplia, transcribe sin embargo tan sólo la partida de bautismo del cabeza de familia, la de su matrimonio, y las partidas de bautismo de sus cuatro hijos. Se ofrecen aquí, ahora, los originales extraídos de la documentación de la iglesia, con su resolución gráfica, así como algunas otras noticias desconocidas hasta ahora, tales como algunas partidas de confirmación, o la partida de bautismo y la de confirmación

13. -Miguel Hilarión EsLava y Elizondo: Museo Orgánico Español: breve memoria histórica de los organistas españoles. Madrid, 1853-1887, pp. 10-11. "Hubo cuatro organistas de relevante mérito con el apellido Nebra: uno lo fue en la Catedral de Cuenca; otro en la de Zaragoza; pero á estos dos sobrepujaron mucho D. Josef en Madrid, y D. Manuel en Sevilla, de quienes debo hacer particular mencion. Fue D. Josef Nebra organista primero de la Real Capilla, y compuso numerosas obras, no solo orgánicas, sino también vocales para el servicio de dicha Real Capilla [...]. D. Manuel Blasco de Nebra, que fue organista de la Catedral de Sevilla y sobrino de D. Josef, siguió las huellas de su tío, y fue su mas fiel imitador. [...]". A continuación, enumera las obras orgánicas que conservaba manuscritas a su muerte el compositor sevillano: obras propias, es decir, de Manuel Blasco de Nebra, 172; de «D. Josef Nebra» [padre, o hijo], 48 obras; de «Nebra, organista de Cuenca» [tal vez Francisco Javier, o tal vez el padre de éste, José Antonio], 6 obras; y de «Nebra, organista de Zaragoza» [por Francisco Javier tal vez, o por Joaquín, más seguramente], 18 composiciones. Repárese en que, a pesar de la afirmación de Eslava, el sevillano Manuel Blasco de Nebra no era sobrino en primer grado de parentesco de los bilbilitanos hermanos Nebra (José, Francisco Javier y Joaquín), sino, propiamente, su sobrino segundo. Y nótese también en que, junto a las obras citadas a su muerte, conservaba otras muchas, entre las que destacan 100 obras de «Soler» [por el padre fray Antonio Soler, que fuera discípulo de José Nebra], o 12 obras (8 fugas y 4 versos) de «Sessé» [por Juan Sessé y Balaguer, discípulo en Zaragoza de Joaquín Nebra, como refiere A. Lozano, op. cit. ]. Curiosamente este último, Juan Sesé, que llegara a organista de la Real Capilla, era cuñado del también músico Joaquín Beltrán, zaragozano nacido en 1736, que fuera organista en la iglesia del Portillo de Zaragoza en 1755 (mientras Joaquín Nebra lo era de la capilla catedralicia de la misma ciudad), así como también organista de la Colegiata del Santo Sepulcro de la ciudad de Calatayud, localidad particularmente ligada a la trayectoria de la familia Nebra. Vemos, pues, cómo las familias y el entorno de muchos músicos de la época - y muy especialmente, de los organistas seglares vinculados laboralmente a la iglesia-, se relacionaban y mezclaban entre sí, consiguiendo de este modo garantizar su continuidad en la profesión, casi a manera de pequeños gremios artesanales de carácter familiar. Y así por ejemplo, los músicos aragoneses apellidados «Nebra» (el padre turolense y sus tres hijos bilbilitanos), los «Blasco» (el padre - aragonés, posiblemente natural de Borja-, [Juan] José [Bernardo Francisco] Blasco [de Nebra] Lacarra, y su hijo, ya sevillano, Manuel Blasco [de Nebra] Orlandi), los «Sesé» (el padre, turolense - de Calanda-, Juan, y su hijo zaragozano, Basilio Sesé y Beltrán), o los «Beltrán» (el tío, Joaquín, que era zaragozano, fue organista de la Colegiata del Santo Sepulcro de Calatayud, 1763-1764, y su sobrino, Basilio, que fuera organista de las Descalzas Reales, de donde anteriormente también lo hubiera sido José Nebra), por no citar a otros cuyas relaciones, muy próximas, todavía quedan por investigar, como en el caso de los hermanos «Moreno y Polo» (José, Juan y Valero), naturales los tres de La Hoz de la Vieja - Teruel一, una localidad pequeñísima de la que, curiosamente, procedía también, aunque algunos años antes, José Antonio Nebra Mezquita, amén de que dichos tres hermanos «Moreno» estuvieron muy vinculados con La Seo de Zaragoza, donde se formaron musicalmente como infanticos; además, en el caso de José Moreno, fue organista segundo en El Pilar, y también lo fue de las parroquias zaragozanas de San Pablo, y de El Portillo (donde antes vimos a Joaquín Beltrán), antes de ocupar la cuarta organistía de la Real Capilla —-donde era primer organista José de Nebra—; como también, en el caso de Juan, es sabido que compitió por la organistía de La Seo zaragozana en 1730 con Joaquín Nebra, que fue quien finalmente ganó la plaza.

14. -José Vicente GonZÁleZ VALLE: “Tradición y progreso en los maestros de música de las catedrales de Zaragoza durante el siglo XVIII", en Estudios de Musicología Aragonesa, Zaragoza, 1977, pp. 35-44. -ID.: Organistas de las Catedrales de Zaragoza. Madrid, Conservatorio Profesional de Música de Zaragoza-Real Musical, 1978. -ID.: "Fondos de música de tecla de D. Scarlatti”, en Anuario Musical, 45 (1990), pp. 103-116.

15. -Dionisio Preciado Ruiz DE Alegría: "Joaquín Nebra (1709-1782) 52 años...”, op. cit., 1977. -ID.: Doce Compositores..., op. cit., 1983. El Nebra de Cuenca se identificaría con Francisco Javier (aunque también estuviera en dicha ciudad su padre); el Nebra de Zaragoza sería Joaquín (aunque también actuara en dicha ciudad su hermano Francisco Javier); el Nebra de Madrid sería el célebre José Melchor; y el Nebra de Sevilla sería el menor de todos ellos, Manuel Blasco de Nebra. El quinto Nebra en cuestión sería el iniciador de la dinastía, José Antonio Nebra Mezquita. 
del padre del célebre Manuel Blasco de Nebra, dilucidando además algunos problemas relacionados con sus nombres, localidades de origen, relaciones familiares, y otros pormenores:

-[Margen:] Joseph Nebra con Rossa Blasco. [Contenido:] "En $\underline{29}$ de Julio de 1697 Casso por Palabras de presente delan / te el S.r Vicario General. Mossen Andres Ballestero Capellan de / dho S.r a Joseph Nebra mançebo organista natural del lugar / de La Hoz del Arzobispado de Zaragoza hijo del $q^{\circ}$ Joseph Nebra / y de Josepha Mezquita coniuges y a Rossa Blasco donzella / natural de la Ciudad de Borja hija legitima del $\mathrm{q}^{\circ}$ Francisco / Blasco y de Manuela Bian coniuges siendo testi / gos de este Matrimonio el D. $r$ Don Gregorio Gomez cano / nigo de esta S.ta Iglesia y Joseph Requejo Ciruxano oieron / La missa nuncial. / Mossen Benito Cabero Reg. te"16.

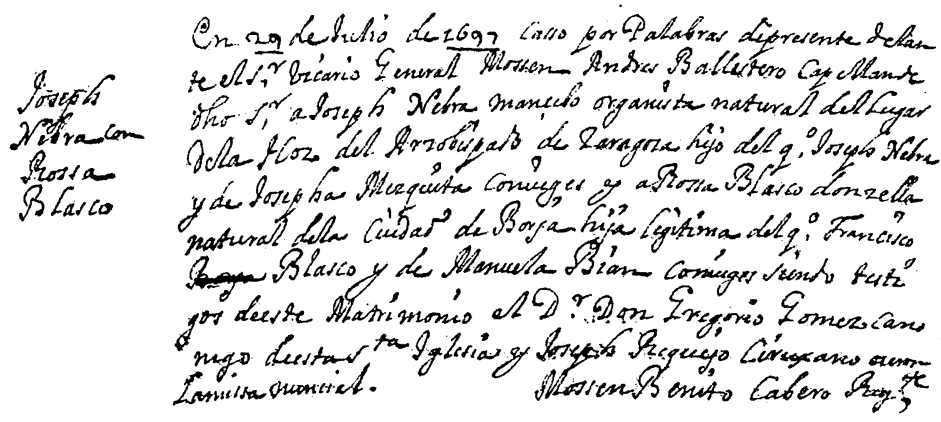

Figura 2

\section{Acta matrimonial de José [Antonio] Nebra Mezquita y Rosa Blasco Bian Colegiata de Santa María (Calatayud -Zaragoza-)}

-[Margen:] Joseph Bernardo Nebra. [Contenido:] "En diez de Abril de mil seiscientos nobenta y nuebe Bautize / yo Mossen Benito Cauero Reg. te a Joseph Bernardo Nebra / hijo de Joseph Nebra y de Rossa Blasco siendo Padri / nos Bernardo Blasco y Chatalina Gomez / Mossen Benito Cauero Reg. te" ${ }^{17}$.

16. Archivo de la Colegiata de Santa María de Calatayud. Quinque Libris: [Portada:] «S.ta Maria / 1665 / hasta 1752 / tomo $2^{\circ}$.». «Libro Quarto, de los que / reciuen el Sacramento del / Matrimonio.». Fol. 76v. [Repárese que el nombre del oficiante de la ceremonia, tal y como se anota en el documento, era «Ballestero», y no «Ballesteros», como transcribió D. Preciado en su artículo para Tesoro Sacro Musical, op. cit., p. 16]. La categoría y "status" de los contrayentes, siquiera sea por su relación con la iglesia, parece clara, pues no les casa el regente de la parroquia, como habría sido lo habitual, sino, con carácter extraordinario, un capellán del vicario general de la diócesis, que parece haber presidido la ceremonia, al tiempo que los testigos son nada menos que un canónigo de la colegial mayor de Santa María (templo que disputara la catedralidad durante largo tiempo a Tarazona, y que de hecho, erigiera anexo a la iglesia un palacio episcopal para que el obispo pudiera residir largas temporadas en la ciudad), y el médico cirujano.

17. Quinque Libris: [Portada:] «S.ta Maria / 1665 / hasta 1752 / tomo $2^{\circ}$.». [Portadilla:] «Libro Primero, de los que / reciuen el Sacramento del / Baptismo.». Fol. 158r. [Adviértase la diversa paginación que ofrece D. PrECIADO (op. cit., p. 16) para este documento]. Por otro lado, dice D. Preciado (p. 16): "Los dos hermanos mayores [por el presente José Bernardo, y por el célebre José Melchor] llevan el mismo primer nombre — José-. Esto podría indicar que, al morir el primer hijo José, 


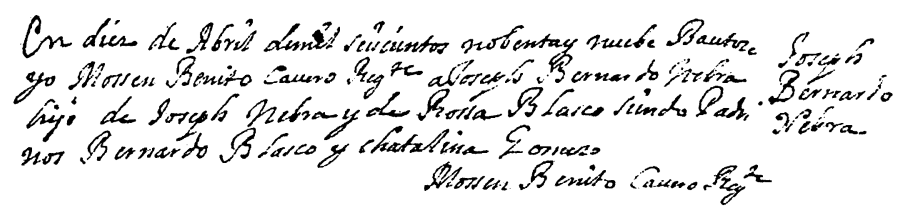

Figura 3

Partida de Bautismo de José Bernardo Nebra Blasco Colegiata de Santa María (Calatayud -Zaragoza-)

-[Margen:] Joseph Melchor Nebra. [Contenido:] "En seis de henero del año de mil setecientos y dos / yo el $\mathrm{R}^{\circ}$. Joseph Sanchez Balssa baptize a Joseph / Melchor Balthasar Gaspar Nebra hijo de Joseph / Nebra y Rosa Blasco. fueron Padrinos Juan / Francisco Nebra, y Innes del Mas. / el Ro. Joseph Sanchez Reg. te" ${ }^{18}$.

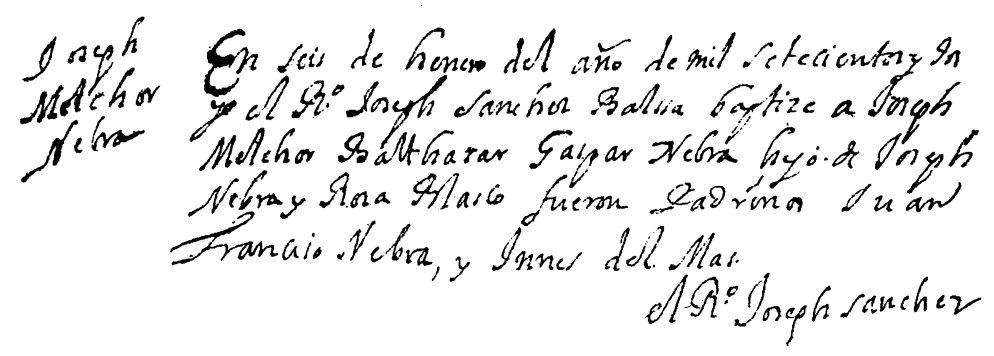

Figura 4

\title{
Partida de bautismo de José [Melchor Baltasar Gaspar] Nebra Blasco Colegiata de Santa María (Calatayud -Zaragoza-)
}

\begin{abstract}
se repitió el mismo nombre en el segundo. Solía ser costumbre". Sin embargo, ha de tenerse en cuenta que no existe Nebra alguno anotado en los años correspondientes en el libro de defunciones, ni en la propia parroquia principal de Santa María, como tampoco en otras iglesias de la ciudad de Calatayud. Y tampoco hemos de perder de vista que otros dos hermanos - y ninguno de ellos falleció de niño-, Francisco Javier, y Joaquín, comparten otro nombre de pila común, «Ignacio». Así pues, aunque puede ser plausible la hipótesis de D. Preciado, pues es cierta la costumbre de que nos habla, no lo es menos que en la época era bastante habitual que se pusieran tres e incluso más nombres de pila a los recién nacidos, entre los cuales solían incluirse el nombre del padre/madre y/o padrinos, como también, frecuentemente, el del santo patrón del día en que tenía lugar el nacimiento o bautizo. De hecho, era relativamente habitual conservar un mismo nombre de padres a hijos, nietos, etc., durante generaciones (y aquí tendríamos p. ej. el caso de este «José»), de suerte que las diferenciaciones entre ellos se limitaban a menudo, en el contexto familiar, a simples diminutivos cariñosos, apodos o motes, o a los segundos o terceros nombres de pila, de suerte que, en la "documentación" oficial que se pudiera generar en la época, era francamente difícil establecer diferencias si éstas no se especificaban esplícitamente, lo que acarrea no pocos problemas a los investigadores en la actualidad. Sea como fuere, tras la documentación conservada en Calatayud, parece perderse para siempre el rastro de este «José Bernardo Nebra», que parece tomar su primer nombre de pila de su padre, y el segundo, de su tío y padrino. Por último, repárese en la madrina del bautizo, una Catalina Gómez, acaso pariente del doctor Gregorio Gómez, canónigo de la colegial de Santa María de Calatayud, a quien veíamos como testigo del matrimonio entre los padres del ahora recién bautizado.

18. Quinque Libris: [Portada:] «S.ta Maria / 1665 / hasta 1752 / tomo $2^{\circ} . »$. [Portadilla:] «Libro Primero, de los que / reciuen el Sacramento del / Baptismo.». Fol. 168v. Entre los padrinos, adviértase la presencia de este «Juan Francisco Nebra», de quien desconocemos más datos y a quien nunca más volveremos encontrar en la documentación bilbilitana, acaso pariente (¿hermano?) del iniciador de la dinastía musical, José Antonio Nebra Mezquita.
\end{abstract}


-[Margen:] Francisco Xavier / Ignacio Benito / Enebra [Contenido:] "En diez y seys de Abril de mil setecientos y cinco / yo el $\mathrm{R}^{\circ}$, Francisco Martinez Bautize a Francisco / Xavier Ignacio Benito Enebra Hijo de Joseph Enebra / y Rosa Blasco siendo Padrinos D.n Juan Pujadas y / Ines Almás / el $\mathrm{R}^{\circ}$ Francisco Martinez Reg. $\mathrm{e}{ }^{19}$.

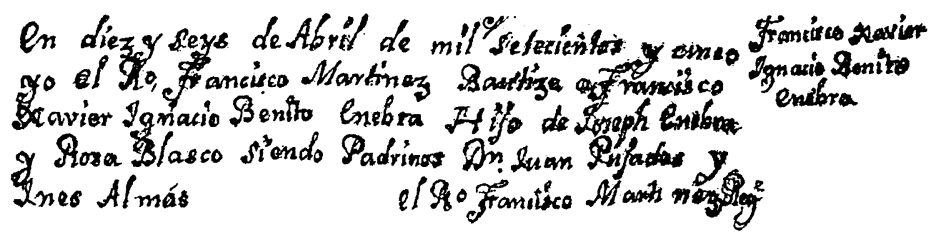

Figura 5

\section{Partida de bautismo de Francisco Javier [Ignacio Benito] Nebra Blasco Colegiata de Santa María (Calatayud -Zaragoza-)}

-[Margen:] Joachin Yg / natio Enebra. [Contenido:] "En beinte i uno de Mayo de mil sietecientos i nuebe yo Mossen Grego- / rio Trasobares Bautize a Joachin Ygnatio Enebra hijo de Joseph Enebra / y de Rosa Blasco, siendo Padrinos Josepha La Carra y Juan Ga- / zeo. / Mos. Gregorio Trasobares Reg"'20.

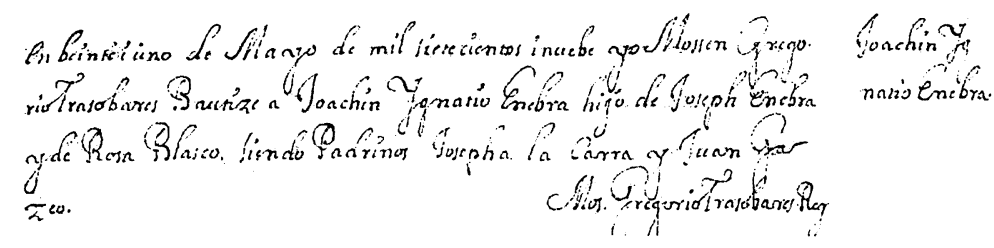

\section{Figura 6 \\ Partida de bautismo de Joaquín [Ignacio] Nebra Blasco \\ Colegiata de Santa María (Calatayud -Zaragoza-)}

19. Quinque Libris: [Portada:] «S.ta Maria / 1665 / hasta 1752 / tomo $2^{\circ}$.». [Portadilla:] «Libro Primero, de los que / reciuen el Sacramento del / Baptismo.». Fol. 185r. [Nótese que, con el cambio de notario, —ahora el regente Francisco Martínez-, los nombres parecen anotarse de modo más descuidado, pues por primera vez se cita en Calatayud al padre, y a su nuevo hijo, como «Enebra», sin duda por efecto fónico, de manera semejante a lo que que sucede con la madrina, citada anteriormente como «del Mas» (en la partida de bautismo de José Melchor), y ahora como «Almás». Repárese además en la coincidencia del nombre propio «Francisco», con el del sacerdote que ahora celebra el bautizo, algo que también sucedió en el caso de José Melchor, en el que además, se tomaba el nombre propio del padre, y el de los santos patronos del día de la Epifanía, los tres reyes magos...].

20. Quinque Libris: [Portada:] «S.ta Maria / 1665 / hasta 1752 / tomo $2^{\circ}$.». [Portadilla:] «Libro Primero, de los que / reciuen el Sacramento del / Baptismo.». Fol. 204r. [El nuevo regente, mantiene la lectura anterior del apellido como «Enebra». El padrino, Juan Gazeo, volverá a aparecer muy pronto, de nuevo como padrino de bautizo del primo de Joaquín Nebra, José Blasco (de Nebra)]. 
-[Margen:] Juan Joseph / Bernardo / Blasco. [Contenido:] "En nuebe de Marzo de mil sietecientos i catorze Bautize yo el Ra- / cionero Gregorio trasobares Regente a Juan Joseph Bernardo Francisco / Blasco hijo de Bernardo Blasco y de Josepha La Carra siendo Padri- / nos Juan Gazeo y Cathalina trasobares. / El Ra ${ }^{\circ}$. Gregorio trasobares Regente"21.

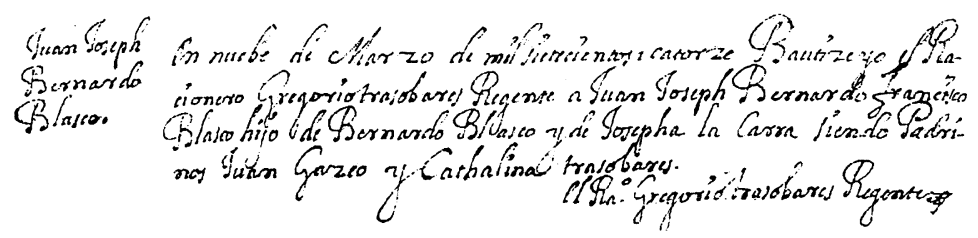

Figura 7

\title{
Partida de bautismo de [Juan] José [Bernardo Francisco] Blasco [de Nebra] Lacarra Colegiata de Santa María (Calatayud - Zaragoza-)
}

\author{
-[Margen:] 123 [Contenido:] Jusepe Enebra hijo de Jusepe y Rosa Blasco 22.

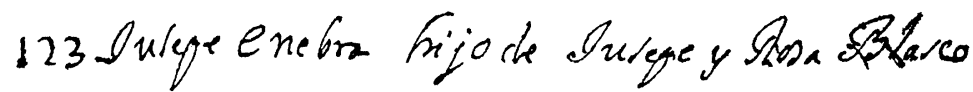 \\ Figura 8 \\ Acta de confirmación de José [¿Bernardo? / ¿Melchor?] Nebra Blasco \\ Colegiata de Santa María (Calatayud -Zaragoza-)
}

\begin{abstract}
21. Quinque Libris: [Portada:] «S.ta Maria / 1665 / hasta 1752 / tomo $2^{\circ}$.». [Portadilla:] «Libro Primero, de los que / reciuen el Sacramento del / Baptismo.». Fol. 225v. [Con esta partida de bautismo se dilucida definitivamente la relación de parentesco existente entre los músicos apellidados «Blasco» y los «Nebra», pues el aquí recién nacido, conocido luego como «José Blasco de Nebra», músico activo en Sevilla, es evidentemente primo hermano de los varios hermanos Nebra también nacidos en Calatayud. Este nuevo niño consta aquí como hijo de Bernardo Blasco. A este último, lo hemos visto como padrino de José Bernardo Nebra, y muy posiblemente, en razón de la posibilidad de lugares y coincidencia de fechas, fuera hijo de Francisco Blasco y Manuela Bian - ambos naturales de Borja-, y por tanto, hermano de la madre de los hermanos músicos, Rosa Blasco (sería, por tanto, tío carnal de los hermanos Nebra, y el ahora recién nacido, su primo hermano). Además, el bebé que aquí se bautiza, consta también como hijo de Josefa Lacarra, a quien ya vimos como madrina en el bautizo de Joaquín Nebra]. Por otro lado, el recién bautizado toma el nombre de pila de su padre, «Bernardo» (nombre que ya tomara también el primero de los hermanos Nebra). Sorprende también que la madrina lleve el mismo apellido que el sacerdote oficiante del bautizo, síntoma posiblemente de una estrecha relación con la iglesia local de esta familia de músicos, aunque seglares, ocupados largo tiempo en puestos bajo manutención eclesiástica.

22. Quinque Libris: [Portada:] «S.ta Maria / 1665 / hasta 1752 / tomo $2^{\circ}$.». «Libro Segundo, de los que / reciuen el Sacramento de / la Confirmacion.». [Fol 25 r.:] "Los hijos de Parrochianos confirma / dos por El Ill. mo Señor Don Blas / Serrate Obispo de Tarazona en / beinte y nuebe de Abril del ano 1703 / en la Iglessia mayor Colegial In / signe de Sancta Maria de esta / Ciudad de Calatayud siendo Pa / drino el Racionero Joseph Martinez". A continuación, se enumeran los niños confirmados, entre los que corresponde a «Jusepe Enebra» el número 123. Se trata éste de un dato desconocido hasta la fecha para la investigación. Caso de que el niño confirmado hubiera sido «José Bernardo Nebra» (dado que, insisto, no se ha hallado constancia documental alguna de que éste hubiera muerto, como sugiere D. Preciado), éste contaría cuatro años casi recién cumplidos; y, caso de aceptar la hipótesis de Preciado, si hubiera sido el aquí confirmado el célebre «José Melchor Nebra», éste tendría, únicamente, algo más de dos años de edad. [Adviértase también aquí, que el nombre de la madre se cita siempre en la documentación bilbilitana como «Rosa Blasco», a pesar de que José Melchor, en su testamento (9-vII-1768), dice ser hijo de «Maria Rosa Blasco». Cfr.: -Mª Salud Álvarez Martínez: José de Nebra Blasco. Vida..., op. cit., 1993, p. 229].
\end{abstract}


-[Margen:] 99 [Contenido:] Rosa Blasco hija de Manuel Blasco y de Maria Oroz ${ }^{23}$.

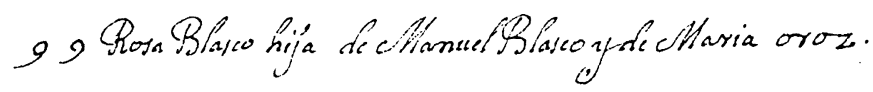

$$
\begin{aligned}
& \text { Figura } 9 \\
& \text { Acta de confirmación de Rosa Blasco } \\
& \text { Colegiata de Santa María (Calatayud -Zaragoza-) }
\end{aligned}
$$

\author{
$\mathrm{Carra}^{24}$.
}

[Margen:] 21 [Contenido:] Joseph Blasco hijo de Bernardo Blasco y de Josepha La

Como puede apreciarse, se trata de una familia netamente aragonesa, cuya cabeza, natural de la localidad turolense de La Hoz, casó con una mujer borjana en Calatayud. Fruto de esta unión se inició el parentesco —en su rama femenina- con la familia Blasco. Según parece, la mujer del cabeza de familia de los Nebra, Rosa Blasco, tendría al menos otros dos hermanos,

23. Quinque Libris: [Portada:] «S.ta Maria / 1665 / hasta 1752 / tomo $2^{\circ}$.». «Libro Segundo, de los que / reciuen el Sacramento de / la Confirmacion.». [Fol 33 r.:] "Los hijos de Parrochianos Confirmados Por el / Ill. mo Señor Don Blas Serrate Obispo de Tara / zana en diez y seis de Julio del Año 1713 / en la Iglesia Mayor Colegial Insigne de San- / ta Maria de esta Ciudad de Calatayud / siendo Padrino el Racionero Phelipe Micheto". A continuación, se enumeran los niños confirmados, entre los cuales corresponde a «Rosa Blasco» el número 99. [Evidentemente, no se trata aquí de nuestra Rosa Blasco Bian, madre de lo hermanos músicos Nebra. Aunque, muy posiblemente, por razón de fechas y coincidencia de parroquia, pudiera tratarse ahora de una niña prima de dichos hermanos músicos, procedente de la rama familiar apellidada Blasco (de Nebra), que daría origen a los músicos que más tarde desarrollarían su actividad en la capital sevillana. Repárese además en que el padre de la niña ahora confirmada se llama «Manuel Blasco»; un nombre de pila coincidente con el de la madre de nuestra Rosa Blasco Bian (madre de los hermanos Nebra), llamada Manuela Bian; de modo, que, la hipótesis de que el matrimonio entre los borjanos Francisco Blasco y Manuela Bian, hubiera podido contar también con un hijo varón al que se hubiera puesto la forma masculina del nombre de pila de la madre, nos ofrecería una posibilidad nada desdeñable. Lo que, en cierto modo, caso de aceptar dicha hipótesis, se habría corroborado al escoger el músico José Blasco (de Nebra) Lacarra, el nombre de pila «Manuel» para su hijo, el conocido Manuel Blasco (de Nebra) Orlandi, que habría así adoptado el nombre de pila de su tío, y de su abuela].

24. Quinque Libris: [Portada:] «S.ta Maria / 1665 / hasta $1752 /$ tomo $2^{\circ}$.». «Libro Segundo, de los que / reciuen el Sacramento de / la Confirmacion.». [Fol 43 r.:] "Los hijos de los Parroquianos de la Iglesia mayor / y collegial Igne de Santa Maria confirmados por el / Illo. S. D. r D. Gregorio Galindo Obispo de Anillo en diez / y ocho de Noviembre del Año de 1727 en dicha Iglesia / siendo Padrino de todos Mossen Thomas Terrer". A continuación, se enumeran los niños confirmados, entre los cuales corresponde a «Joseph Blasco» el número 21. [Se trata aquí del acta de confirmación, hasta ahora desconocida, del que fuera más tarde conocido músico José Blasco (de Nebra) Lacarra, padre del célebre Manuel Blasco (de Nebra) Orlandi. Contaría entonces algo más de trece años de edad]. Sobre la rama familiar de los Blasco, puede verse: -Ma Salud ÁlvarEZ MARTínez: "José y Manuel Blasco de Nebra: la otra cara de la familia de Nebra Blasco", en Revista de Musicología, xv/2-3 (1992), pp. 775-813. Afortunadamente, con la presente documentación que ahora se aporta, se dilucida definitivamente aquella afirmación que se hacía en el citado artículo, en el sentido de que "aunque se desconoce la fecha de nacimiento de José Blasco (de Nebra) Lacarra, sí se sabe que nació en la ciudad de Calatayud [...]” (op. cit., p. 777). 
Manuel y Bernardo Blasco, respectivamente, aunque esto no se explicite entre la documentación de que disponemos en Calatayud ${ }^{25}$. En cualquier caso, el matrimonio José Nebra-Rosa Blasco permaneció en Calatayud varios años - al menos doce-, naciendo ahí cuatro de sus hijos y al menos un sobrino, y confirmándose uno de sus hijos (Jusepe) y dos sobrinos (Rosa Blasco y José Blasco). La primera noticia expresa de la estancia de los Nebra en Calatayud es de 1697; la última, es de 1709; cuando el padre de la familia de músicos, José Antonio, accede a su nuevo puesto en la seo de Cuenca, en 1711, se dice que procede de Calatayud, lo que bien podría querer decir que allí siguió la familia entre 1709 y el mencionado año 1711; mientras tanto, la última vez que se cita a los Blasco en la ciudad aragonesa, es en 1727.

En cuanto a sus nombres de pila, resultan francamente difíciles de diferenciar, dado que el cabeza de familia, «Joseph» [Antonio] Nebra Mezquita, tenía idéntico nombre y primer apellido que su padre, y el mismo nombre de pila que su madre, Josepha. A su vez, y manteniendo la tradición familiar, puso por nombre de pila «Joseph» a dos de sus hijos, mientras que uno de sus sobrinos, apellidado Blasco, también era de nombre «Joseph».

En cuanto al primer hijo del matrimonio, acerca del cual en alguna publicación se ha dicho que habría fallecido tempranamente, sin embargo, habiendo sido bautizado, no aparece su nombre entre los óbitos de la colegial, por lo que tal vez no haya que desestimar que fuera él y no su siguiente hermano en edad y de igual nombre, quien fuera confirmado en Calatayud. En todo caso, si se hubiera producido el fallecimiento de dicho niño en la ciudad en que su familia residía, éste debería haber sido convenientemente registrado entre la documentación de la iglesia -en el correspondiente libro de defunciones-, puesto que, como cristiano bautizado, habría habido obligación de ello. Sin embargo, la posible e hipotética muerte del primer hijo del matrimonio, no aparece documentada entre los libros de la colegiata bilbilitana (?). Por otro lado, la familia se enriquece más aún si tenemos en cuenta al tal «Juan Francisco Nebra» que apadrinó el bautizo del luego célebre José Melchor, de quien, muy probablemente, fuera su tío (es decir, que José Antonio Nebra Mezquita y este Juan Francisco habrían sido, acaso, hermanos).

Tampoco la correcta escritura del apellido parece quedar muy clara, anotándose indistintamente como «Nebra» o «Enebra», según quién sea el encargado de anotar la documentación pertinente. Sobre este aspecto ya trató en su día D. Preciado. Pero los apellidos, en Calatayud, no aparecen nunca como «de Nebra» (si bien es cierto que, años más tarde, el propio José Melchor se firmará a menudo como «José de Nebra», muy posiblemente con la intención de "ennoblecer" su apellido mediante la adición del "de"). Y, sea como fuere, parece claro que las

25. Según declara D. Francisco Pérez Miraval, vecino de Sevilla, se informa que Manuel Blasco de Nebra es "nieto por linea Paterna de don Bernardo Blasco de Nebra natural de la ciudad de Borja reino de Aragon, y de doña Josefa Gertrudis Lacarra natural de Calatayud [...]. todos defuntos de los quales solo a conocido el testigo al ordenando y a sus padres" [cfr. -Francisco José SEnRA Lazo: “Apuntes biográficos de Manuel Blasco de Nebra...”, op. cit., 1993, p. 22]. Ello quiere decir que, efectivamente, Rosa Blasco y Bernardo Blasco eran hermanos, y ambos naturales de la localidad de Borja (Zaragoza). La mujer aparecida en la documentación bilbilitana como «Josepha La Carra», sería al parecer natural de Calatayud y su nombre de pila completo sería pues el de «Josefa Gertrudis». Muy posiblemente, esta Josefa Lacarra tuviera lazos familiares con el canónigo prebendado de La Seo de Zaragoza llamado José Diego Lacarra, lo que explicaría asimismo las conexiones de José Antonio Nebra y sus hijos con el cabildo zaragozano. 
familias Blasco, y Nebra, respectivamente, son dos familias diferentes aunque emparentadas. Si se cruzaron sanguíneamente, parece lógico que debieran llamarse Nebra Blasco, en lugar de Blasco Nebra (aunque en este último caso, resulta ya evidente que la rama familiar «Blasco» añadió a continuación por su cuenta el «de Nebra», que en puridad ya no les correspondía, seguramente para darse a conocer).

La confusión en este sentido parece partir del [Juan] Joseph [Bernardo] Blasco Lacarra (hijo de Bernardo Blasco y de Josepha La Carra) que fue bautizado y confirmado en Calatayud ${ }^{26}$, que es el mismo que fallecería el 19-X-1785 en Sevilla, según nos corrobora su testamento otorgado en la ciudad del Guadalquivir. Éste, fue nombrado en 1735 organista segundo de la Catedral de Sevilla, habiendo sido antes organista "de la Sta Igl. de Zaragoza"27. Utilizaba entonces el nombre de «José Blasco de Nebra», por lo que todo hace suponer que añadiría a su apellido la coletilla «de Nebra», que no le correspondía en rigor sino en carácter de parentesco, con el fin de ser más fácilmente reconocido como miembro de una familia de músicos ampliamente repartida y conocida por todo el territorio español para aquel entonces. Tal vez pensara que el empleo de dicho apellido «Nebra» podría facilitarle un mejor acceso a las plazas músicas a las que aspiraba (?). Casado en Sevilla, tuvo ocho hijos, en el testamento de uno de los cuales - de su hija Felipa concretamente-, ésta se declara ser hija de «Juan José Blasco y Lacarra». Ese primer nombre de pila «Juan», nos confirma su nombre completo (Juan Joseph Bernardo) aparecido en su partida de bautismo, a pesar de que en su confirmación sólo se le nombre como «Joseph», que parece ser sería el nombre que utilizaría más habitualmente. Quinto hijo de nuestro Juan Joseph Bernardo Blasco y Lacarra, nacería el que luego sería célebre músico, conocido como «Manuel Blasco de Nebra» ${ }^{28}$,

26. Juan Joseph Bernardo Blasco y Lacarra (*Calatayud, 1714; †Sevilla, 1785). En su testamento declara llamarse "Don Josef de Blasco y Nebra, nattural de Calatalutt, Reyno de Aragon, vezino de estta de Sevilla en la Collacion de Santta Cruz, hijo lexittimo de Don Bernardo Blasco y Doña Josefa LaCarra, defunttos, natturales y vezinos que fueron de aquella Ciudad" [vid.: -Francisco José Senra Lazo: "Apuntes biográficos de Manuel Blasco de Nebra...”, op. cit., 1993, pp. 25-26]. Vid. también: -Ma Salud Álvarez Martínez: "Blasco (II). 1. Blasco [de Nebra] Lacarra, José. 2. Blasco [de Nebra] Orlandi, Manuel", en Diccionario de la Música Española e Hispanoamericana. Vol. 2. Madrid, sGAe, 1999, pp. 522-524.

27. Cfr. Acta capitular de la Catedral de Sevilla, del 3-XII-1735. Años más tarde, sería nombrado maestro del facistol en la seo hispalense. Para las conexiones de los Nebra y los Blasco con la ciudad de Zaragoza, véase: -Miguel Hilarión Eslava y Elizondo: Museo Orgánico Español..., op. cit., pp. 10-11. -Antonio Ezquerro Esteban, ed.: Antonio Lozano González: «La Música..., op. cit., 1994, pp. 52-53, 58 y 113. -Dionisio Preciado Ruiz de Alegría: "Joaquín Nebra (1709-1782). 52 largos años...", op. cit., 1977, pp. 12-17 y 40-45. -ID.: Doce Compositores..., op. cit., 1983. -Francisco José SENRA LAzo: "Apuntes biográficos de Manuel Blasco de Nebra...", op. cit., 1993.

28. Manuel [Felix Vicente Joseph Francisco Cypriano] Blasco [Orlandi Lacarra Vandersteyn] (*Sevilla, 1750; †Id., 1784), más conocido como «Manuel Blasco de Nebra». Su partida de bautismo - correspondiente a la iglesia parroquial de la Santa Cruz de Sevilla - le hace «hijo de Don Joseph Nebra, y Blasco [sic. Juan Joseph Bernardo Blasco y Lacarra], y de Doña Aquilina [Josefa] Orlandi [y Vandersteyn] su legítima muger». En 1766 este músico, conocido como ya hemos dicho, como «Manuel Blasco de Nebra», se desplazaría a la corte de Madrid para estudiar música con su tío Joseph Melchor Nebra. En 1768 [cfr. acta capitular de la Catedral de Sevilla del 9-IX-1768] fue nombrado (se le cita como «Manuel de Nebra») organista segundo de la Catedral de Sevilla en las ausencias y enfermedades de su padre (a quien se cita como Joseph de Nebra). Según el expediente de Corona y Primeros Grados n 23 del año 1773, Manuel Blasco de Nebra declara ser «Hijo legítimo de Don Josef Blasco de Nebra, y de Doña Aquilina Orlandi» [vid. -Francisco José SenRa Lazo: “Apuntes biográficos de Manuel Blasco de Nebra...", op. cit., 1993, p. 20]. Como puede verse, él se cita a sí mismo y a su padre con el «Blasco» en primer lugar, añadiendo posteriormente el «de Nebra»; reafirma ello nuestra idea de que el «de Nebra» que habían perdido [nótese el «de»] fuera utilizado, tanto por él como por su padre, como distintivo familiar de prestigio. No parece tenerse esto por ilegítimo, cuando, en declaración ante el párroco de Santa Cruz en Sevilla, el 29-XI-1773, "contesta bajo juramento a preguntas del Párroco que se llama don Manuel Blasco de Nebra, y que es natural de esta ciudad y hijo lexitimo de lexitimo matrimonio de don Juan 
aunque, como vamos viendo, el apellido «Nebra» con el que estaba directamente emparentado, ya no le correspondiera en rigor ${ }^{29}$.

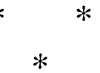

En Zaragoza

Documentalmente, por cuanto conocemos hasta la fecha, la presencia de la familia Nebra en las catedrales zaragozanas se inicia con Francisco Javier. De hecho, parece que la relación de la familia con la capital aragonesa se mantuvo siempre con la catedral metropolitana de El Salvador (vulgo "La Seo"), y no así con El Pilar.

Respecto a las referencias de posibles puestos musicales en dicha catedral a cargo del padre de la dinastía, José Antonio Nebra, y aun del iniciador musical de la rama Blasco, José Blasco (de Nebra), no se han hallado hasta el momento referencias concretas ${ }^{30}$. Y sobre la presencia de Francisco Javier Nebra en la organistía de La Seo, ya M. Querol y D. Preciado ofrecieron en su día la documentación capitular conservada ${ }^{31}$. Sin embargo, hasta que no se emprendiera la catalogación exhaustiva de los fondos musicales conservados en el archivo de música de las catedrales de Zaragoza, bajo la dirección de José V. González Valle, no se reparó en la existencia e importancia de una fuente verdaderamente excepcional, directamente relacionada con Francisco Javier Nebra: un volumen manuscrito, cuidadosamente anotado y encuadernado, fechado en Roma el 26 de Marzo del año 1727, con las suites para clavicémbalo de "il caro

Joseph B̀lasco de Nebra natural de Calatayud Obispado de Zaragoza, y de doña Aquilina Horlandi natural de esta ciudad que ambos viven oi en ella" [vid. -Francisco José SENRA LAZO: op. cit., p. 21]. Y según se corroboran poco después los datos sobre sus padres (según declara D. Francisco Pérez Miraval, vecino de Sevilla), se informa que Manuel Blasco de Nebra es "nieto por linea Paterna de don Bernardo Blasco de Nebra natural de la ciudad de Borja reino de Aragon, y de doña Josefa Gertrudis Lacarra natural de Calatayud = Y nieto por linea Materna de don Pedro Dionicio Horlandi, y Anaya natural de esta ciudad y de doña Maria Cristina Armans, y Vanderstein natural de Amberes en Flandes. todos defuntos de los quales solo a conocido el testigo al ordenando y a sus padres" [cfr. -Francisco José SENRA LAZO: op. cit., p. 22]. Al parecer, no se conservan obras de los «Blasco de Nebra» en la seo hispalense, aunque sí de José (Melchor) Nebra Blasco. Véase: -Herminio GoNzález Barrionuevo; José Enrique Ayarra Jarne; y Manuel Vázquez Vázquez: Catálogo de Libros de Polifonía de la Catedral de Sevilla. Granada, Centro de Documentación Musical de Andalucía, 1994 [obras de José Nebra en pp. 528-532].

29. En este sentido, creo oportuno rectificar las conclusiones a que llega Dionisio Preciado en su libro Doce Compositores..., op. cit., 1983, p. 37; ahí señala lo siguiente: "Finalmente, Eslava cita (el primero de la lista) [en su Museo Orgánico] a Manuel Blasco de Nebra, que era sobrino de los tres anteriores [por José Melchor, Francisco Javier, y Joaquín Ignacio Nebra] e hijo de alguna hermana de los mismos y, por ende, nieto del fundador de la dinastía de organistas José Nebra Mezquita". Sin embargo, como estamos demostrando, Manuel Blasco de Nebra no fue sino sobrino segundo de los tres Nebras citados; esto es, era hijo de un primo hermano (Juan Joseph Bernardo Blasco y Lacarra) de José Melchor, Francisco Javier y Joaquín Ignacio. Por tanto, no era «hijo de alguna hermana de los mismos» sino de un primo de ellos (Juan Joseph Bernardo Blasco y Lacarra), ni era nieto "sanguíneo" de José Nebra Mezquita, sino sobrino-nieto de la mujer de éste, Rosa Blasco, como nieto directo del hermano de Rosa, Bernardo Blasco.

30. Recordemos aquí que los Nebra mantuvieron relaciones con un pariente suyo, prebendado de La Seo de Zaragoza, llamado José Diego Lacarra. (Cfr.: -Ma Salud Álvarez Martínez: José de Nebra Blasco. Vida..., op. cit., 1993 [vid. p. 15]. (Agradezco al Excmo. Cabildo Metropolitano de Zaragoza las facilidades dadas para la realización de este trabajo).

31. -Miguel Querol Gavaldá: Cantatas y canciones para voz solista..., op. cit., 1973, p. 12. -Dionisio PRECIADO Ruiz de Alegría: "Joaquín Nebra (1709-1782). 52 años largos...", op. cit., 1977, pp. 12-17. -ID.: "Joaquín Nebra (17091782). 52 años largos...", op. cit., 1977, pp. 40-45. -ID.: Doce Compositores..., op. cit., 1983.

Anuario Musical, 57 (2002) 
Sassone", Georg Friedrich Händel ${ }^{32}$. Una copia verdaderamente temprana, tan sólo siete años posterior a la primera edición de la obra del gran maestro anglo-alemán (Suites de pièces pour le clavecin, Londres, John Cluer, 14-XI-1720).
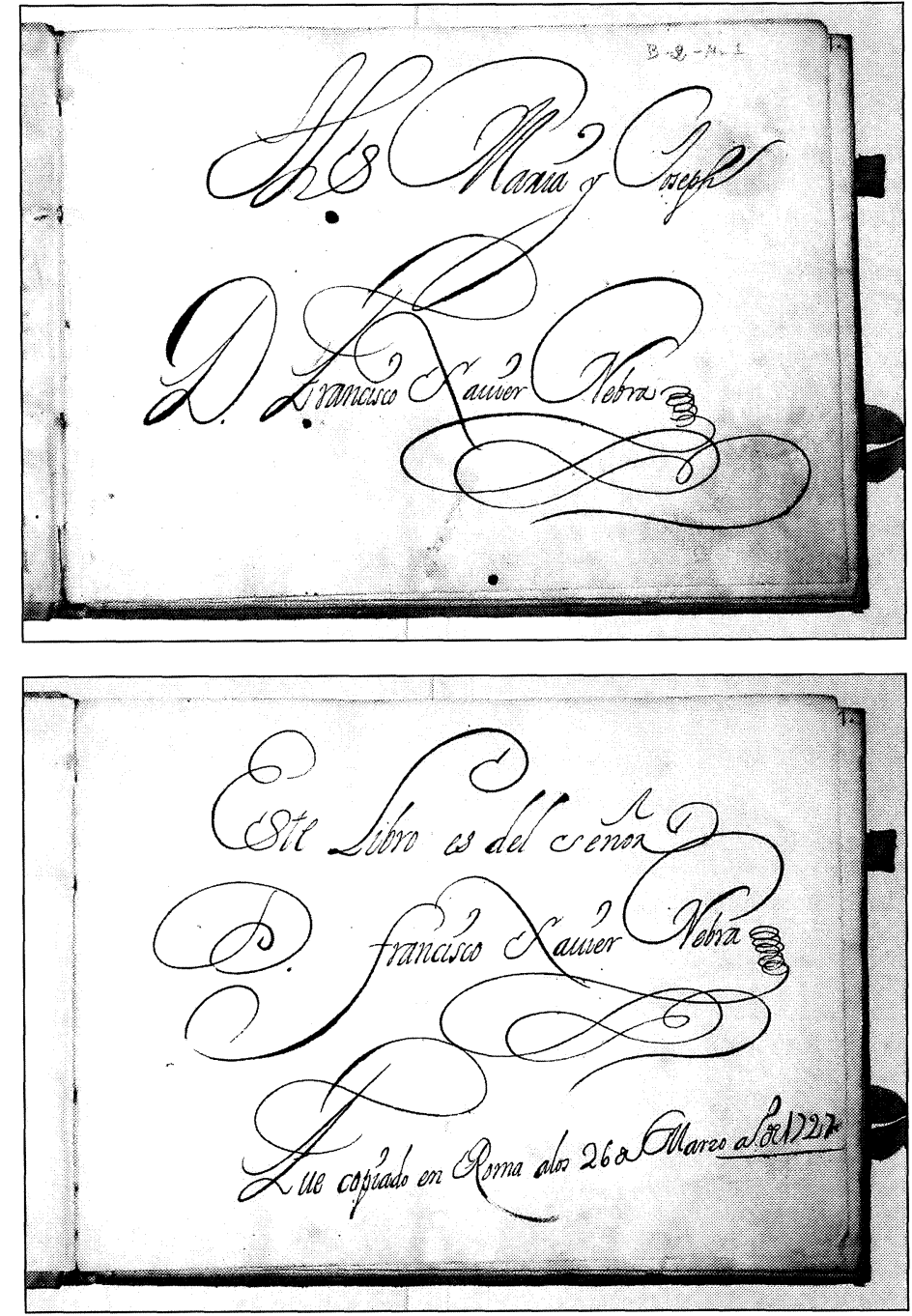

Figura 11

Primera portadilla del volumen manuscrito con las Suites para clave de G. F. Händel, propiedad de Francisco Javier Nebra.

Archivo de Música de las Catedrales de Zaragoza [E: Zac, B-2 Ms. 1]
Figura 12

Segunda portadilla. Volumen con las Suites para clave de G. F. Händel, propiedad de Francisco Javier Nebra. (Roma, 26-III-1727). Archivo de Música de las Catedrales de Zaragoza [E: Zac, B-2 Ms. 1]

32. El equipo encargado de la catalogación del mencionado archivo musical (José V. González Valle, Luis A. González Marín, y A. Ezquerro Esteban), ya dio hace algún tiempo noticia de esta pieza excepcional en el catálogo de una exposición interdisciplinar de ámbito local, relacionada con el patrimonio histórico-cultural de la iglesia zaragozana. Cfr.: -Luis Antonio GonzÁlez MARín: "[Suites para Clave de G. F. Händel]", en El espejo de nuestra historia. (La diócesis de Zaragoza a través de los siglos). Zaragoza, Edelvives, 1991, p. 322. En la mencionada ficha catalográfica se señala que "uno de los más singulares ejemplos de la modernidad de algunos organistas y maestros de capilla zaragozanos es, sin duda, la colección de las ocho grandes suites para clave de Händel, reunidas cuidadosamente en un manuscrito copiado, con toda probabilidad, del impreso original (Suites de pièces pour le clavecin, Londres, 1720) tan sólo siete años después de su publicación. [...] Desconocemos si Francisco Javier Nebra [...] fue enviado a Roma para completar su formación y a su regreso fue admitido al servicio de La Seo, o tal vez poseía buenos contactos en Italia y este libro - y quizá otros más - le fue enviado a Zaragoza”. 


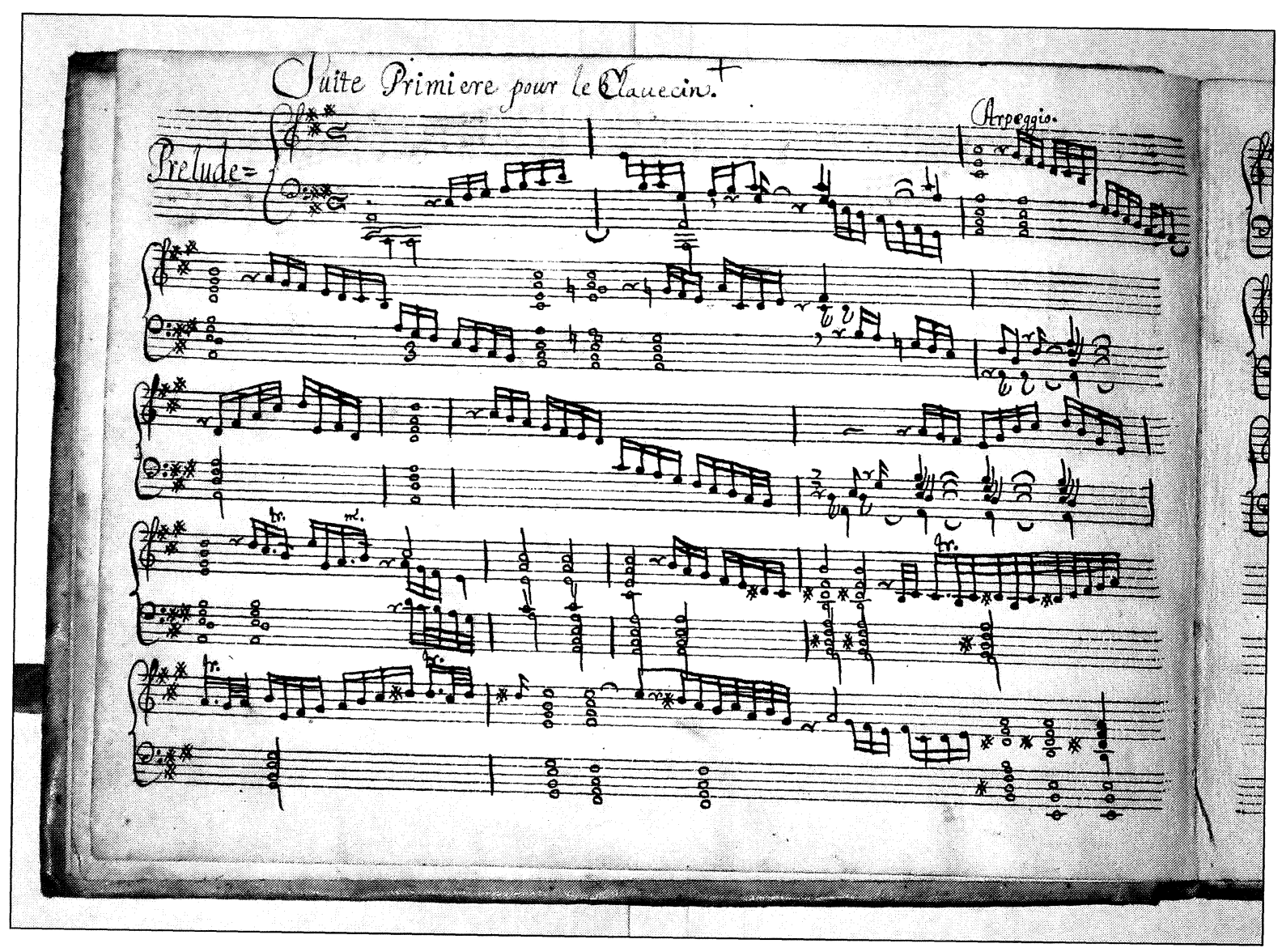

Figura 13

Volumen manuscrito con las Suites para clave de G. F. Händel, propiedad de Francisco Javier Nebra. (Roma, 26-III-1727). Suite $N^{\circ} 1$ en La Mayor ( $H W V$ 426) Archivo de Música de las Catedrales de Zaragoza [E: Zac, B-2 Ms. 1]

Se trata de un volumen manuscrito de $21,5 \times 29 \mathrm{~cm}$., encuadernado en pergamino y con ataduras en piel, anotado sobre soporte papel. Viene foliado originalmente del 1 al 44, páginas a las que se añaden todavía otros dos folios previos más sin numerar — con sus lados recto a modo de portadillas, y sus lados vuelto en blanco-, más otro folio al final del volumen, asimismo sin numerar, a modo de contraportada. Los fols. 1r., y 44v., están en blanco, aunque aparecen pautados. La primera portadilla, en su lado recto, reza: «Jhs Maria y Joseph / D. Francisco Xauier Nebra [rubricado]» ${ }^{33}$. Mientras que la segunda portadilla, en su lado recto, lee: «Este Libro es del

33. Por cuanto se ha podido comprobar partir de las obras musicales de miembros de la familia Nebra conservadas en Zaragoza, este tipo de encabezamiento alusivo a los tres miembros de la Sagrada Familia y a otros santos, es típico, no sólo de Francisco Javier, sino también de su hermano más célebre, José [Melchor], y de Joaquín (Vid. Figura 14 y Figura 22). 
Señor / D. francisco Xauier Nebra [rubricado] / Fue copiado en Roma, a los 26 de Marzo $a^{\circ}$ de 1727». Por su parte, el folio que sirve a modo de contraportada, en su lado recto, finaliza con la conocida fórmula «Finis Coronat Opus», mientras que en su lado verso se anota nuevamente: «Soy del S.r D. Francisco / Xauier Nebra [rubricado]». La insistencia por dejar bien patente que la propiedad del volumen pertenecía a Francisco Javier Nebra, podría querer sugerirnos, al menos, un par de ideas: en primer lugar, el alto valor que su propietario podría haberle concedido, o bien, en segundo término, el celo con que éste quería preservar para sí una obra, que, (acaso por lo atractiva para otros compositores coetáneos del contexto próximo a Francisco Javier Nebra, pues se trataba de una obra reciente, procedente de Roma, y de un autor de prestigio y escasa penetración hasta entonces en territorio hispánico), sin duda, habría servido como reclamo para ser manejada por terceros, copiada, etc.

En cuanto a los contenidos reflejados en este libro, se anotan las 8 suites de Pièces pour le Clavecin (HWv 426-433), aunque compuestas muy posiblemente en Londres entre 1710 y 1717 (la primera pieza de la colección dataría del año 1717 aproximadamente), recopiladas para su edición en $1720^{34}$. De hecho, el propio Händel anotó, en el prefacio a dicha primera edición a cargo del impresor John Cluer, lo siguiente:

"I have been obliged to publish some of the following Lessons, because surrepticious and incoherent copies of them had got Abroad. I have added several new ones to make the work more usefull".

Las quejas de Händel respecto a la proliferación de copias no autorizadas de sus obras —las cuales habían alcanzado el extranjero-, debían incluir no sólo las abundantes copias manuscritas que circulaban en la época, sino también, entre otras, una edición pirata a cargo de John Walsh —editor más tarde de muchas de sus obras_- quien, para esta ocasión, se había servido de un nombre falso: "Jeanne Roger, Amsterdam"35.

El maestro, prometía, con su autorizada edición de 1720, proseguir las ocho suites publicadas $^{36}$ con otras nuevas, si es que éstas primeras gozaban de buena acogida. Sin embargo, no lle-

34. La datación de los autógrafos originales no está clara todavía. Se ha querido sugerir que Händel habría compuesto estas suites para el uso de su alumna, la Princesa Ana de Inglaterra (de modo similar a otras piezas que el maestro de Halle destinara a la Princesa Carolina, o a la hija menor del rey Jorge II, la Princesa Luisa, para quien Händel escribiera las suites para clave en Re menor y en Sol menor). En todo caso, estas "piezas", denominadas por el propio Händel como «Lessons», denotan en su escritura una cierta intencionalidad y carácter didácticos, pedagógicos, que tal vez fueran los que atrajeran a Francisco Javier Nebra para su uso.

35. Cfr. -Graham Pont: "Handel's Keyboard Overtures: Problems of Authentication and Interpretation", en Studies in Music, 21 (1987), pp. 39-68 [cita concreta en p. 39].

36. Se anotan en las siguientes tonalidades: Suite $N^{\circ} 1$, en La Mayor (hwv 426); Suite $N^{\circ} 2$, en Fa Mayor (hwv 427); Suite $N^{o} 3$, en Re menor (hwv 428); Suite $N^{\circ} 4$, en Mi menor (hwv 429); Suite $N^{\circ} 5$, en Mi Mayor (Hwv 430); Suite $N^{\circ} 6$, en Fa\# menor (HWv 431); Suite $N^{\circ} 7$, en Sol menor (hwV 432); y Suite $N^{\circ} 8$, en Fa menor (hwV 433). Aunque todas se agrupan bajo el término de «suites», no todas siguen un mismo patrón o estructura. Así por ejemplo, las suites 1,4 y 8 , siguen el esquema más tradicional de la suite de danzas, particularmente del tipo germano (un preludio y/o fuga, más una alemana, correnda, [sarabanda] y giga); las suites 3 y 5, posiblemente por influencia de Johann Jakob Froberger, incluyen ya temas con variaciones tras la correnda (en la $\mathrm{N}^{\circ} 5 \mathrm{p}$. ej., el célebre tema del "Herrero armonioso"); la suite/sonata 2 - partiendo del modelo de Arcangelo Corelli-, adopta el esquema de la sonata da chiesa italiana (Adagio, Allegro, Adagio, Allegro [Fuga]); y la suite 7 responde al modelo de suite "a la francesa" (Obertura, Andante, Allegro, Sarabanda, Giga, Pasacalle [Chacona]); mientras que la suite 6 combina elementos de la suite de danzas germana con otros de la sonata da chiesa. Como apuntes curiosos, po- 
garía a realizarlo hasta haber recopilado una segunda colección entera, que no se imprimiría sino hasta 1733, y ahora ya a cargo del editor John Walsh.

De modo que el ejemplar manuscrito zaragozano, goza de una datación verdaderamente temprana, aparte de su interesante origen - Roma - y la gran calidad de su copia. Hasta la fecha, el libro de Francisco Javier Nebra con piezas para clave de Händel, no aparece reflejado ni en los repertorios ofrecidos por el RISM (Répertoire International des Sources Musicales), ni tampoco en el catálogo temático de G. F. Händel ${ }^{37}$.

Naturalmente, nos queda aún la duda de si el volumen zaragozano, tan esmeradamente copiado y encuadernado, se trata como parece de una copia autógrafa a cargo del propio Francisco Javier Nebra, o bien se trata únicamente de una copia que el mencionado músico aragonés encargara sacar a otra persona, para su uso, en la capital italiana, y que luego él hubiera firmado para garantizar su propiedad. En todo caso, las dos portadillas que encabezan el volumen vienen rubricadas, de modo que podríamos aventurar que el propio Nebra, además de propietario evidente del volumen, hubiera podido actuar también como copista, en cuyo caso habría estado en Roma en la primavera de 1727.

Si aceptáramos la hipótesis anterior, la siguiente pregunta, sin duda, sería averiguar qué motivos habrían conducido al joven Nebra hasta Roma, cuánto tiempo habría permanecido en dicha ciudad, y con qué músicos habría contactado, además de cómo y en qué lugar en concreto de la Ciudad Eterna habría tenido conocimiento de la obra de Händel, o cómo habría podido financiar una copia tan lujosa, además de cómo habría llegado el volumen a Zaragoza, pues se copió el 26 de Marzo de 1727, y poco tiempo más tarde, concretamente el 14 de Agosto del mismo año, Nebra comenzaba ya a ocupar la organistía de La Seo de Zaragoza. F. J. Nebra tendría entonces tan sólo 22 años de edad... ¿Llegaría entonces a Zaragoza desde Roma? ¿Le habría suministrado la copia algún contacto suyo allá, que la trajera de regreso consigo? [...] En todo caso, y a falta de más datos al respecto y de realizar un análisis caligráfico y estilístico, las respuestas a estas preguntas quedarían para más adelante. Y sea como fuere, la presente obra demuestra que los músicos Nebra estaban muy al tanto de las últimas novedades musicales europeas, y de su afán por disponer, para su uso y disfrute (estudio, ejecución) de la mejor literatura para tecla de la época ${ }^{38}$.

dríamos apuntar aquí que a la Suite $\mathrm{N}^{\circ}$ 5, también conocida como «The Harmonious Blacksmith» (el herrero armonioso), se la denomina en ocasiones como "Air and Variations». Y en cuanto a la Suite $N^{\circ} 7$, ésta deriva de la obertura orquestal de la cantata «Clori, Tirsi e Fileno» (Hwv 96), que luego sería usada por el propio Händel para su «Oreste» (HWV 11).

37. -Walter EISEN; y Margret EISEN, eds.: Händel Handbuch. Band 3. (Thematisch-Systematisches Verzeichnis: Instrumentalmusik; Pasticci; Fragmente). [Vol. 3 de la obra en 5 tomos a cargo de la «Georg-Friedrich-Händel-Stiftung»]. Kassel-Basilea-Londres, Bärenreiter, 1986, p. 212 y ss.

38. De estos mismos años data muy probablemente la llegada al archivo musical catedralicio de Zaragoza (posiblemente merced al quehacer e intereses de organistas destacados de La Seo, como Francisco Javier Nebra o su hermano Joaquín), de importantes repertorios de la mejor música para tecla de carácter internacional, como por ejemplo: $a$ ) la colección en tres volúmenes impresos del antecesor de J. S. Bach como Kantor en la «Thomasschule» de Leipzig, Johann Kuhnau, titulada Frische Clavier Früchte oder Sieben Suonaten von guter Invention und Manier auff dem Claviere zu Spielen (Dresde y Leipzig, Johann Christoph Zimmerman, 1710); b) las Pièces de Clavecin de François Couperin (París, Du Plessy / Belangé, 1713), conservadas en un bello volumen impreso encuadernado en piel; o bien, $\boldsymbol{c}$ ) la magnífica serie de obras manuscritas -cuidadosamente copiadas y encuadernadas - de Domenico Scarlatti (217 sonatas suyas conservadas en cuatro tomos, más algunas otras en cuadernillos sueltos), que, junto a los de Venecia y Parma, conforman en Zaragoza el mayor corpus documental de la época a nivel internacional con composiciones de este autor. 
Tras la presencia de Francisco Javier en La Seo de Zaragoza, y con su paso a Cuenca en 1729 , donde compaginaría con su padre los principales puestos musicales catedralicios (su padre, maestro de capilla, y él, organista), se produciría la llegada a la organistía del templo del Salvador de Zaragoza del hermano menor bilbilitano de la familia Nebra, Joaquín ${ }^{39}$. También sobre el proceso para cubrir la plaza de organista de La Seo a la marcha de Francisco Javier Nebra, D. Preciado ha ofrecido alguna documentación ${ }^{40}$. Y sin embargo, a propósito de las interesantes oposiciones que ganara el benjamín aragonés de los Nebra, D. Preciado resume el proceso de los exámenes, de suerte que únicamente ofrece el comienzo de los ejercicios (es decir, lo acaecido en el primer día de los cuatro que se precisaron para dilucidar la plaza), más la resolución final con los resultados del proceso de oposición ${ }^{41}$. Dado no obstante el interés de los ejercicios que se pidieron a los aspirantes a la organistía de la iglesia metropolitana de Zaragoza (puesto que nos da idea de la pericia técnica que se exigía a los profesionales del teclado en nuestras iglesias), y por el interés añadido de comprobar cuáles fueron las calificaciones de quien más tarde obtuvo la plaza, Joaquín Nebra, transcribo a continuación el proceso completo de la oposición ${ }^{42}$ :

[Fol. 1r:]

"Ilmo. Señor.

En cumplimiento del encargo que se nos ha hecho por parte de V. I. para asistir, y examinar los organistas que han concurrido a la oposicion de la Plaza Vacante, en la S.ta Iglesia Metropolitana y S.to Templo del Salvador. Decimos los abajo firmados que con dictamen, y aprobacion de los SS. nombrados por V. I. para esta Junta se hizo en la forma siguiente dando principio el dia 6 de Marzo del presente año.

\section{Dia primero.}

Se les pidio a todos, y a cada uno que tañesen un lleno de estudio, un partido de mano derecha, otro de mano izquierda, y que tañesen con intento, o, sin el sobre las seis voces de la musica que son ut: re: mi: fa: sol: la: la: sol: fa: mi: re: ut:, y que echasen contrapunto sobre canto llano y se les dio una voz de un paso ${ }^{43}$ para que lo entrasen con el organo y para escribirlo despues: Y haciendo la mas seria reflexion sobre la ejecucion de lo dicho decimos en cumplimiento de nra obligacion y en descargo de nuestras conciencias que en lo que tañeron estos dias debe estar en $=$

39. No ofrezco aquí los datos referentes a la búsqueda de sustituto para Francisco Javier Nebra en Zaragoza, la correspondiente elección de Joaquín Martínez, hijo del conocido Joaquín Martínez de la Roca (quien, a su vez, había sido maestro de capilla anteriormente en El Pilar), y la imposibilidad de aquél, residente en Toledo, para posesionarse de la plaza de organista en La Seo, pues de todo ello ya se ha dado cumplida cuenta con anterioridad. (Vid.: -Dionisio PRECIADO RUIZ DE Alegría: Doce Compositores..., op. cit., 1983, pp. 38-39).

40. -Dionisio Preciado Ruiz De Alegría: “Joaquín Nebra (1709-1782). 52 años largos...”, op. cit., 1977, pp. 1217. -ID.: "Joaquín Nebra (1709-1782). 52 años largos...", op. cit., 1977, pp. 40-45. -ID.: Doce Compositores..., op. cit., 1983, pp. 35-41. [Se repite en este último volumen buena parte de la información ofrecida en los dos artículos anteriores].

41. Vid.: -Dionisio Preciado Ruiz de Alegría: Doce Compositores..., op. cit., 1983, pp. 46-48.

42. Vid.: Actas capitulares de La Seo de Zaragoza (ejemplar de El Pilar), del 6 al 10 de Marzo de 1730 («1730/ Siendo secretario el S.or Blancas / Alm. 2 Caj. 2 Ag. $\left.1 \mathrm{n}^{\circ} 40 »\right)$. [Contenido copiado en cuatro folios sueltos sin numerar, el último en blanco, que se insertan entre los fols. 22 y 23 ].

43. D. Preciado (Doce Compositores Aragoneses..., op. cit., p. 47) cita aquí, posiblemente por error de lectura, "se les diese una voz de un bajo". 
Primer lugar = Ignacio Subias, organista de la Catedral de Bique.

Segundo lugar $\quad=\quad$ Joaquin Nebra y en el mismo segundo lugar Manuel Sierra organista en la colegial de Soria y asimismo Juan Moreno y Polo.

Tercero lugar = Antonio Marzal organista en la Parroquia de San Lorenzo de Huesca, el de Pamplona y el organista de la Colegial de Borja.

En el intento que se les dio sobre ut, re, mi, fa, sol, la,

$\begin{array}{lll}\text { Primer lugar } & = & \text { Ignacio Subias. } \\ \text { Segundo lugar } & = & \text { Polo y Sierra. } \\ \text { Tercero lugar } & = & \text { Nebra. } \\ \text { Cuarto lugar } & = & \text { El de Pamplona y Huesca. } \\ \text { Quinto lugar } & = & \text { El de Borja. }\end{array}$

[Fol. 1v:]

En el paso que entraron y despues escribieron,

Primer lugar $=\quad$ Subias, con el defecto de no haber cerrado el paso con clausula final, pero lo entro con mas novedad que los otros. En el mismo primer lugar para el paso el de Pamplona con

$\begin{array}{lll}\text { Segundo lugar } & = & \begin{array}{l}\text { defecto de haber estado } \\ \text { Tebra y Sierra. }\end{array} \\ \text { Tercero lugar } & = & \text { Polo y el de Huesca }{ }^{44} \\ \text { Cuarto lugar } & = & \text { El de Borja. }\end{array}$

En los contrapuntos que se pidieron, Primer lugar $=$ Polo.

Segundo lugar $\quad=\quad$ Subias y Sierra.

El de Borja, Huesca y Pamplona no hicieron cosa de provecho y Nebra nada.

Concluyendo este dia se les dio intento para que por tiempo de 24 horas trabajasen una licion, que entregaron el dia 7 , y despues de vistas a toda nuestra satisfaccion,

\begin{tabular}{lll} 
Primer lugar & $=$ & Subias. \\
Segundo lugar & $=$ & Sierra. \\
Tercero lugar & $=$ & Polo, y el de Pamplona. \\
Cuarto lugar & $=$ & Nebra. \\
Quinto lugar & $=$ & El de Huesca y el de Borja nada \\
\multicolumn{1}{r}{ Se comenzo el ejercicio tañendo su licion cada uno y en } \\
Primer lugar & $=$ & Subias. \\
Segundo lugar & $=$ & Sierra. \\
Tercer lugar & $=$ & Polo y Nebra. \\
Cuarto lugar & $=$ & El de Huesca y el de Pamplona \\
& & el de Borja nada.
\end{tabular}

44. D. Preciado (íbid., p. 47), sólo cita aquí a Polo, sin mencionar a "el de Huesca".

45. A partir de aquí, se ofrecen datos inéditos (no aportados en la bibliografía mencionada de D. Preciado). 
Despues se pidio tañesen un verso sobre el Aue Maris stela.

[Fol. 2r:]

Primer lugar

$=\quad$ Subias.

Segundo lugar $\quad=\quad$ Sierra, Polo, Nebra.

Tercero lugar $=$ El de Borja.

Cuarto lugar $\quad=\quad$ El de Pamplona y Huesca.

Pidioseles otro verso sobre el Pange lingua.

$\begin{array}{lll}\text { Primer lugar } & = & \text { Subias. } \\ \text { Segundo lugar } & = & \text { Sierra, Nebra, Polo, y el de Pamplona. } \\ \text { Tercero lugar } & = & \text { El de Borja, y el de Huesca. }\end{array}$

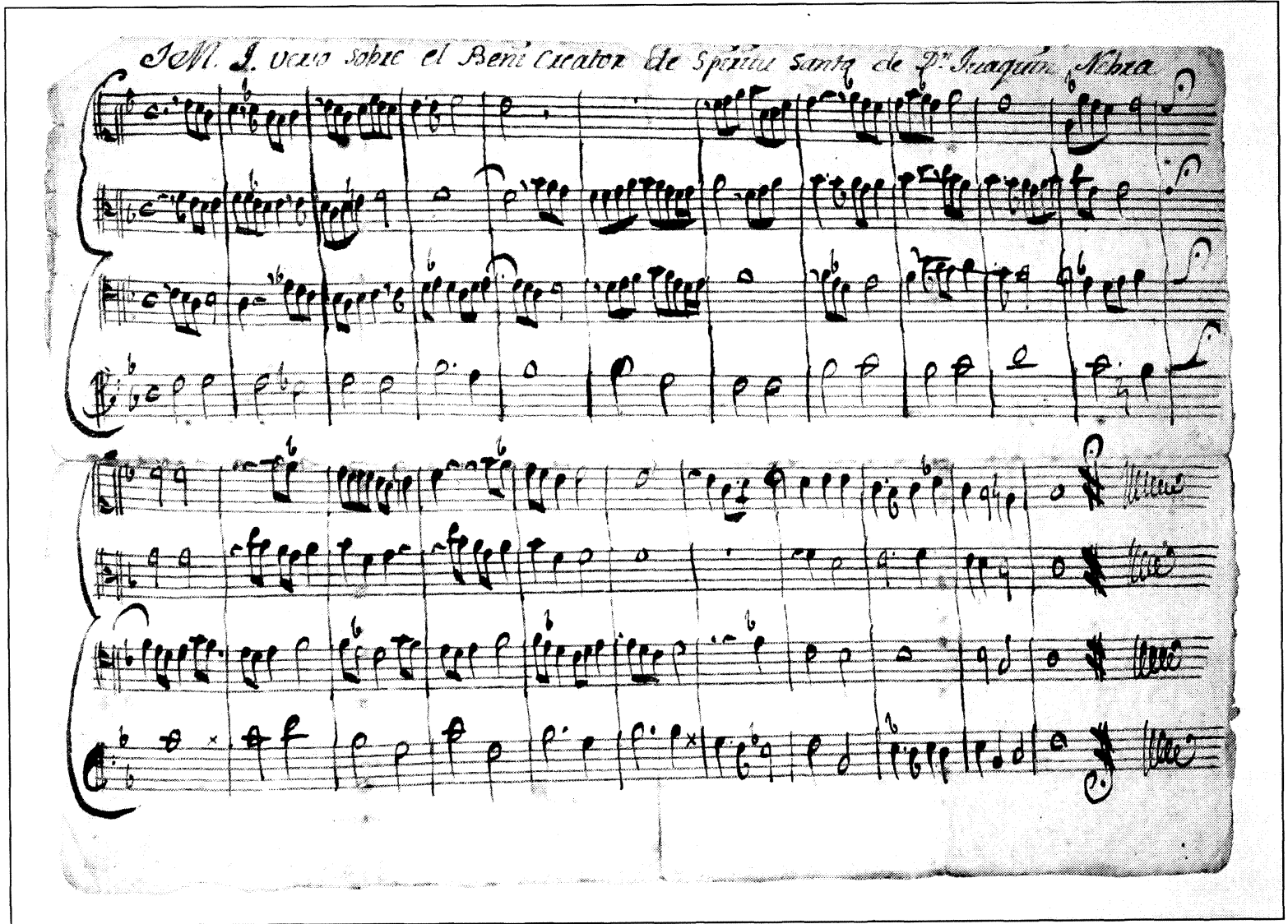

Figura 14

Verso para órgano sobre el himno «Veni creator», de Joaquín Nebra. (A parecido en una colección de ejercicios de oposiciones de organistas). Archivo de Música de las Catedrales de Zaragoza [E: Zac, D-536] 

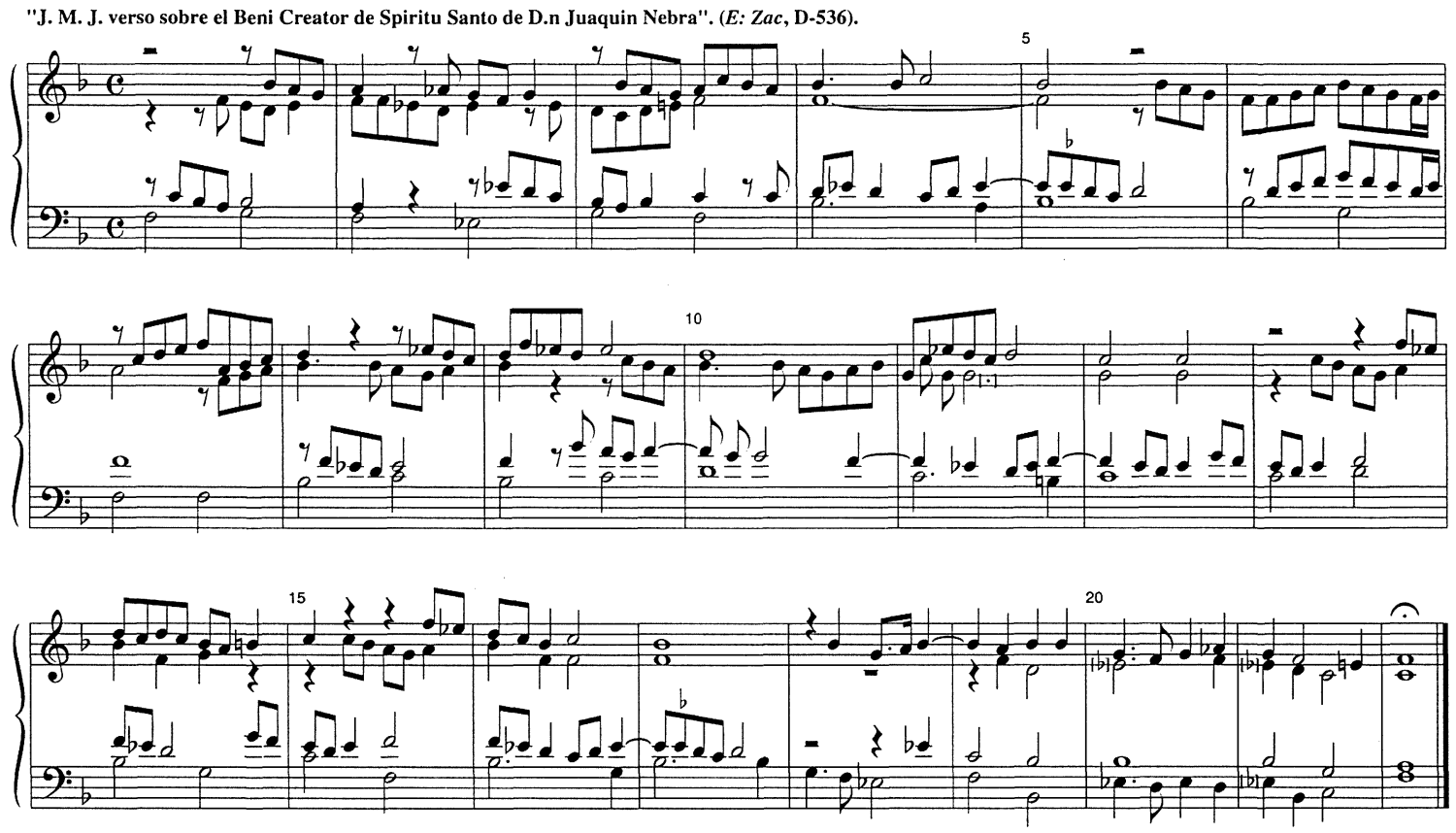

Figura 15

Edición de la pieza anterior [E: Zac, D-536]

En las clausulas que se pidieron por 7. mo tono punto alto,

Primer lugar = Subias.

Segundo lugar $\quad=\quad$ Sierra.

Tercero lugar $\quad=\quad$ El de Pamplona, Huesca y Borja.

Cuarto lugar $\quad=\quad$ Polo.

Quinto lugar $\quad=\quad$ Nebra.

Despues de entonar un sochantre introito y Kirie,

Primer lugar $=$ Subias.

Segundo lugar $\quad=\quad$ Nebra, Borja y Polo.

Tercero lugar $\quad=\quad$ Sierra, el de Pamplona y Huesca.

Pidioseles que con organo y cadereta tañesen a su voluntad.

Primer lugar $=$ Subias.

Segundo lugar $\quad=\quad$ Pamplona, Sierra y Borja.

Tercero lugar $\quad=\quad$ Nebra, Polo y el de Huesca.

Dioseles un Bajete para poner sobre el tres voces con el que termino este dia.

Primer lugar $=$ Subias.

Segundo lugar $\quad=\quad$ Pamplona y Polo.

Tercer lugar $\quad=\quad$ Sierra y Nebra.

Cuarto lugar $\quad=\quad$ El de Huesca, el de Borja nada. 


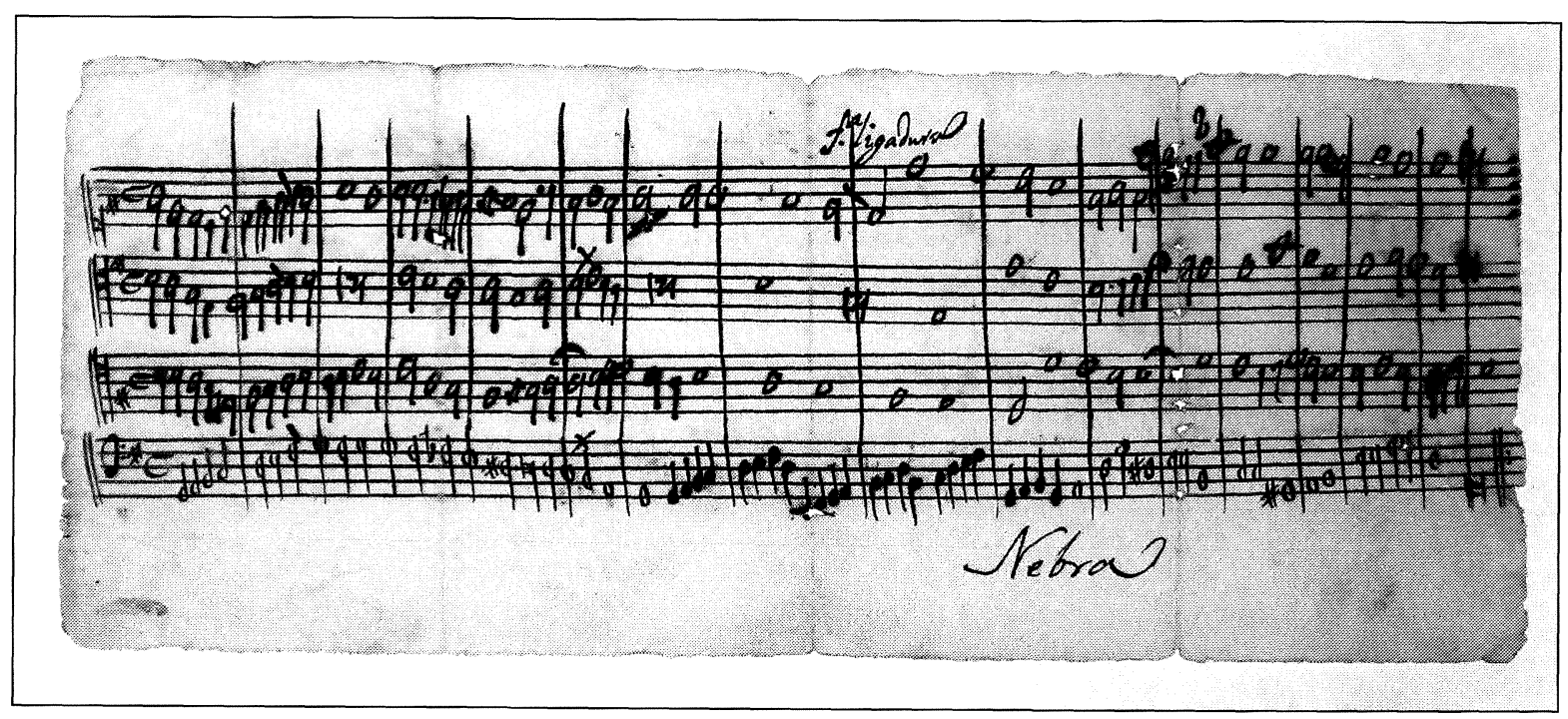

Figura 16

Ejercicio para órgano (un Bajete), de «Nebra» [seguramente, de Joaquín Nebra]. (Aparecido en una colección de ejercicios de oposiciones de organistas). Archivo de Música de las Catedrales de Zaragoza [E: Zac, D-536]
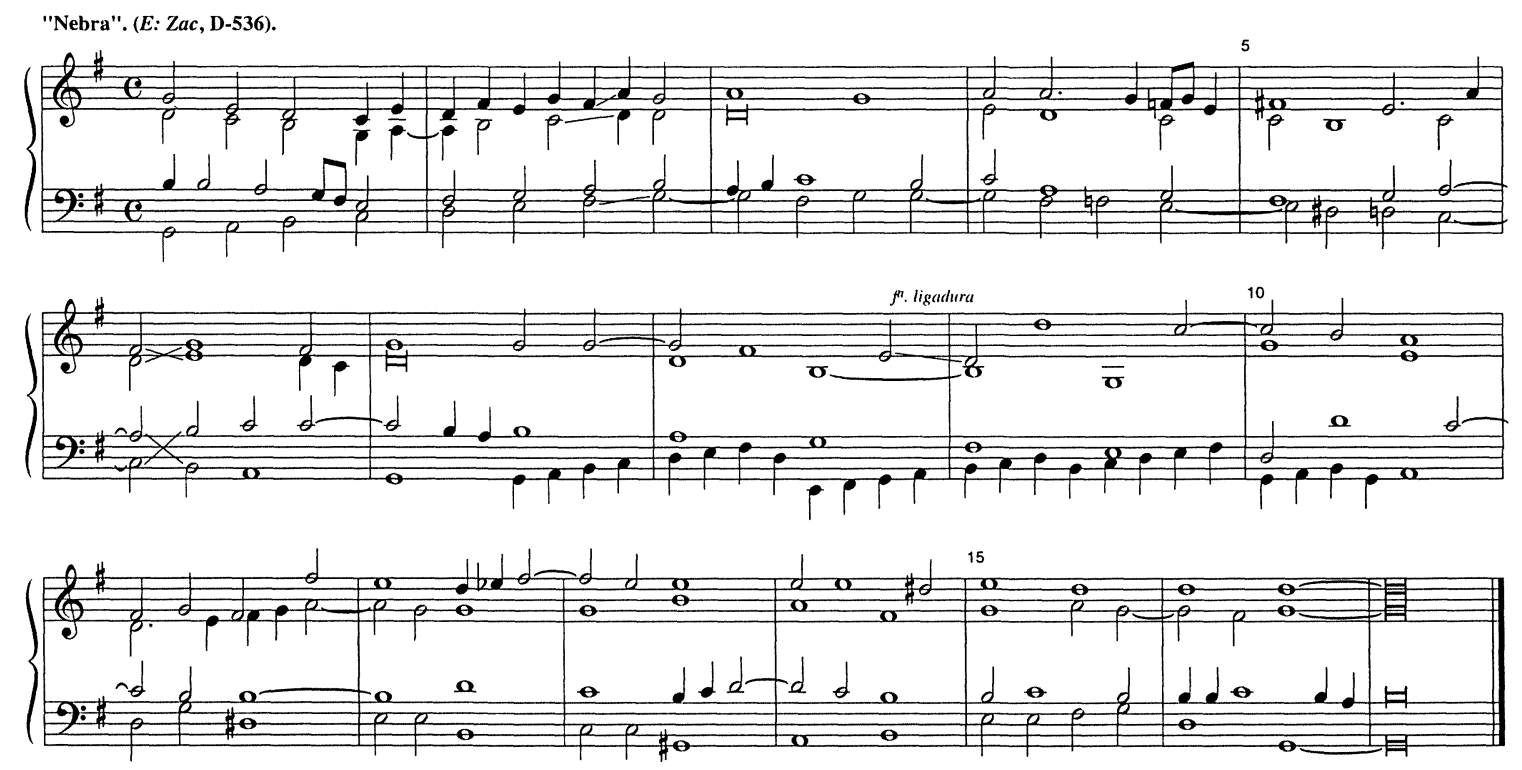

Figura 17

Edición de la pieza anterior [E: Zac, D-536] 
Dia $3^{\circ}$ que fue a 9.

Se comenzo el ejercicio acompañando un villancico.

Primer lugar = Subias y Sierra.

[Fol. 2v:]

Segundo lugar $\quad=\quad$ Polo y Pamplona.

Tercero lugar $\quad=\quad$ Nebra, Borja y Huesca nada.

Siguiose el acompañar un Magnificat a 8.

$\begin{array}{lll}\text { Primer lugar } & = & \text { Subias. } \\ \text { Segundo lugar } & = & \text { Polo. } \\ \text { Tercer lugar } & = & \text { El de Pamplona. } \\ & & \text { Nebra, Huesca, Sierra, y el de Borja nada. }\end{array}$

Despues acompañaron un 4.

Primer lugar $=$ Subias.

Segundo lugar $\quad=\quad$ Polo.

Tercero lugar = Sierra, Nebra y Pamplona.

El de Borja y Huesca nada.

Acompañaron dos versos de $8^{\circ}$ tono y segundillo.

Primer lugar $=$ Polo y Nebra.

Segundo lugar $=\quad$ Subias, Sierra, Borja, Huesca y el de Pamplona.

Se dio fin a este dia con tañer de su eleccion.

Primer lugar $=$ Subias.

Segundo lugar = Polo, Nebra y Pamplona.

Tercero lugar $=\quad$ Sierra, Borja y Huesca.

Dia cuarto que fue a 10.

Se dio principio cantando los musicos un Kirie y por el intento que tañeron,

Primer lugar $=$ Sierra.

Segundo lugar $\quad=\quad$ Subias y Polo.

Tercero lugar $=$ Pamplona.

Nebra, el de Huesca y el de Borja nada.

Acompañaron una tonada.

$\begin{array}{lll}\text { Primer lugar } & = & \text { Subias. } \\ \text { Segundo lugar } & = & \text { Polo. } \\ \text { Tercer lugar } & = & \text { El de Pamplona. } \\ \text { Cuarto lugar } & = & \text { Sierra y Borja. } \\ & & \text { Nebra y Huesca nada. }\end{array}$

[Fol. 3r:]

Tañeron musica cromatica.

Primer lugar $\quad=\quad$ Subias y Nebra.

Anuario Musical, 57 (2002) 
$\begin{array}{lll}\text { Segundo lugar } & = & \text { El de Pamplona, Huesca y Sierra. } \\ \text { Tercero lugar } & = & \text { Polo. Borja nada. }\end{array}$

Tañeron por 6 tono punto Bajo.

Primer lugar $\quad=\quad$ Subias, Sierra, Huesca, Nebra y el de Pamplona.

Polo y Borja nada.

Tañeron de su eleccion.

Primer lugar $\quad=\quad$ Subias.

Segundo lugar $\quad=\quad$ Nebra.

Tercero lugar $=\quad$ Sierra, Huesca, Borja, Pamplona y Polo.

$\underline{\text { Resultando }}$

de la graduacion de los cuatro dias de examen, que ${ }^{46}$

Subias

Sierra $\quad=$

Polo $\quad=$

Nebra $\quad=\quad$ Tres veces en primer lugar, siete veces en segundo, seis en

Pamplona $\quad=\quad$ Dos veces en primer lugar, siete en segundo, nueve en

Huesca $\quad=\quad$ Una vez en primero, otra en segundo, siete en $3^{\circ}$, cuatro en

cuarto, una en quinto, y en cinco cosas sin grado.

Borja $\quad=\quad$ Tres veces en segundo lugar, siete en tercero, una en cuarto, dos en quinto y diez veces sin grado.

\section{Dictamen}

Habiendose adquirido diez y nueve veces el

[Fol. 3v:]

primer lugar Ignacio Subias por esto y el grande exceso que lleva a todos sus coopositores en la licion de las veinte y cuatro horas y en acompañar queda en

Primer lugar = Ignacio Subias.

Segundo lugar $\quad=\quad$ Sierra, Polo, Nebra y el de Pamplona.

Tercero lugar $\quad=\quad$ El de Huesca.

Cuarto lugar $\quad=\quad$ El de Borja.

Asi lo sentimos. Zaragoza y Marzo 10 del 730.

Luis Serra Maestro de Capilla Jph Lanuza Maestro de Capilla Thomas Soriano org.ta ${ }^{47}$.

46. D. PRECIADo retoma aquí el hilo de la narración, que en su resumen había abandonado, a propósito de estas oposiciones (Doce Compositores..., op. cit., p. 47).

47. Luis Serra, maestro de capilla de El Pilar de Zaragoza (desde 1717 hasta su muerte en 1759); José Lanuza, maestro de capilla de La Seo de Zaragoza (desde 1727); y Tomás Soriano, organista de El Pilar (que lo era al menos desde 1718, y se jubiló en 1782). Los opositores se identifican del modo siguiente: Ignacio [¿Ignacio Manuel?] Subías, organista de 
En cuanto al desarrollo de las oposiciones, una vez presentada al cabildo de La Seo la "graduación" de los aspirantes que había estimado finalmente el tribunal examinador, el capítulo metropolitano se planteó al parecer una única cuestión:

"si solamente se habia de votar por Manuel Subias, consultado solo el primer lugar o si entrarian los del segundo, tercero y cuarto, a lo que resolvio se votase con caxuelas, protextandolo el S.r Presidente y votandose por pluralidad de votos se determino entrasen todos en la votacion, la que hecha quedo elegido y nombrado Joaquin Nebra" ${ }^{48}$.

En la anterior resolución definitiva habría varios aspectos a considerar, pues da la impresión de que el cabildo (a pesar de la aplastante victoria "técnica" de Ignacio Subías en la oposición, a quien posiblemente los capitulares - y ya no tanto los profesionales músicos en plantilla en Zaragoza - no conocieran de cerca $)^{49}$, no quería renunciar a la posibilidad de que entraran en liza, al menos, los tres candidatos que se habían situado "ex aequo" en segundo lugar (Manuel Sierra, Juan Moreno y Polo, y Joaquín Nebra).

la Catedral de Vic; Manuel Sierra, organista de la colegial de San Pedro de Soria [en el catálogo de dicha iglesia únicamente se registran composiciones de un tal «Alejo Sierra» $(* 1799 ; \dagger 1851)(?)$. Véase: $-M^{a}$ Montserrat SÁNCHEZ SISCART; y Jesús GonZalo LóPEZ: Catálogo del archivo musical de la concatedral de San Pedro apóstol de Soria. Zaragoza, Caja Salamanca y Soria, 1992, pp. 321-327]; Juan Moreno y Polo, de 19 años (procede de la propia capilla de La Seo, donde había finalizado su formación como infante de coro); Joaquín Nebra Blasco, de 20 años (procede de Cuenca); Andrés de Escaregui Mendiola, organista de la Catedral de Pamplona, de 29 años; Antonio Marzal, organista en la Parroquia de San Lorenzo, en Huesca; Jorge Remírez, organista de la Colegial de Santa María, en Borja.

48. Actas capitulares de La Seo, 11-III-1730.

49. Desconocemos datos sobre este "Ignacio Subías» procedente de Vic, aunque años atrás había desarrollado su actividad como compositor, también en ámbito catalán, un "Jaime Subías» con quien tal vez habría que emparentar a nuestro músico. Este Jaime Subías fue maestro de capilla en la colegiata de Santa María del Mar en Barcelona (1684), así como de la seo de Manresa (1684-1696-[1701]). Aparece ahí gozando ya el tratamiento de «reverendo». En 1696, gravemente enfermo, pasó desde Manresa con permiso a restablecerse a Vic (de donde posiblemente fuera originario), poniéndosele por sustituto entretanto al sochantre Joan Bernat. En 1698, cuando constaba todavía como maestro efectivo en Manresa - aunque ausente por enfermedad-, escribió a su cabildo pidiendo que, dado lo prolongado de su mala salud, se otorgara su plaza a su hermano, "Carlos Subías» (quien fuera maestro en Manresa, desde 1699 hasta 1701, en que pasó a Gerona). En 1701, al dejar su hermano Carlos la ciudad de Manresa, todavía constaba, al parecer, como maestro titular —ausente todavía-. Se conservan varias obras suyas en el denominado «Fondo Verdú» de la Biblioteca de Catalunya en Barcelona. Algunos indicios (?) señalan que pudo haber sido luego maestro de capilla en la Catedral de Vic, para pasar nuevamente a ocupar el magisterio de Manresa (1713-1726). Sin embargo, es preciso tomar estos últimos datos con cierta cautela, habida cuenta de la confusión existente entre este Jaime o Jaume Subías, y su hermano Carlos, a quienes ahora se uniría tal vez el Ignacio Subías opositor en 1730 a la organistía de La Seo de Zaragoza. ¿Sería nuestro Ignacio sobrino del sacerdote Jaime, o hijo -o acaso también sobrino- del seglar Carlos? De momento, carecemos de datos suficientes para afirmar una u otra cosa, si bien la coincidencia de empleos, apellidos, procedencia, e incluso fechas, resulta más que notoria. Entretanto, Carlos Subías, acudió en 1699 a Manresa como maestro regente en ausencia de su hermano, pues "si bé estàn contents [los capitulares de Manresa] dels bons serveis de l'actual regent Joan Bernat, no obstant fa falta un altre sustentor del cor". Pero Carlos no debió dar buenos resultados, pues "no ensenyaba als minyons i no tenia cap que es pogués dir minyó per cantar", de modo que el cabildo manresano, sintiéndose burlado, exigió venir nuevamente a Jaime, su titular, a quien se cita como "el Mestre de Vic". Efectivamente, el 14-x-1700, el reverendo Jaime Subías, que estaba en Vic, contestó a su cabildo de Manresa, excusándose por no acudir a su llamada. Tras lo cual, el capítulo manresano acordó despedir al sustituto Carlos Subías, dándole un plazo para acomodarse en otro lugar, lo que hizo en 1701 al marcharse a Gerona. [Agradezco estas informaciones a Glòria BALLús GASóliva, quien amablemente me ha cedido datos inéditos del capítulo segundo ("Història de la Música a Manresa i a la Seu, a través dels documents conservats") de su tesis doctoral en curso, titulada La Música a la col-legiata basílica de Santa Maria de la Seu de Manresa: 1714-1808 - Universitat Autònoma de Barcelona-]. Por otro lado, puede consultarse la edición de alguna de las composiciones de Jaime Subías en: -Antonio EzQuerro ESTEBAN: Tonos humanos, letras y villancicos catalanes del siglo XVII. Barcelona, CSIC, «Monumentos de la Música Española, LXV», 2002. También Josep PAVIA I Simó menciona unos textos impresos de cuatro villancicos de «J. Subías», en: La música en Cataluña en el siglo xvill. Francesc Valls (167lc1747). Barcelona, CSIC, «Monumentos de la Música Española, LIII», 1997, p. 129. 
De hecho, de los tres mencionados, parece que se estuviera pensando únicamente en los dos últimos, si tenemos en cuenta que incluso parece confundirse el nombre de Subías (Ignacio), con el de Sierra (Manuel), - algo que no había sucedido en ningún momento entre los profesionales examinadores-, al llamarse en la resolución capitular al primero «Manuel Subías» [sic.].

Precisamente, podría haber tenido aquí mucho que ver el hecho de que Juan Moreno y Polo acababa de salir como infante de coro, en cuyo desempeño habría coincidido con sus dos hermanos (José, y Valero, respectivamente), y que todos ellos, aparte su ascendencia aragonesa, debieron aprovechar magníficamente su formación musical catedralicia ${ }^{50}$. De hecho, el mayor de los hermanos, José, actuaba como organista segundo en El Pilar, y años más tarde serviría el órgano de parroquias zaragozanas como San Pablo, o Nuestra Señora del Portillo ${ }^{51}$. Muy posiblemente, el afianzamiento zaragozano de los hermanos (v. g., uno de ellos, Valero, llevaba por nombre de pila el del santo patrón de la catedral y de la ciudad), no se habría visto con malos ojos por su cabildo — que les había facilitado su formación-, lo que debería ir aparejado, naturalmente, de su propia valía técnico-musical ${ }^{52}$. Por su parte, no es preciso imaginar mucho para suponer que, en el caso de Joaquín Nebra, habría podido contar, para que se le permitiera entrar en la votación, su ascendencia aragonesa, así como la familia de la que procedía, pues seguramente su padre habría sido bien conocido del cabildo de La Seo (organista en Calatayud y en Cuenca, seguramente contaba con excelentes contactos en Zaragoza), como sobre todo, su hermano Francisco Javier, quien había dejado recientemente la plaza por motivos bien comprensibles (acudir junto a su padre y demás familia en una catedral no muy lejana). Y además, contaba con un pariente (José Diego Lacarra) entre los prebendados de La Seo. No habría que desdeñar en este sentido, que, tras fallar en Zaragoza la prevista elección de Joaquín Martínez (otro hijo de un maestro de capilla que ocupara anteriormente la plaza en El Pilar), los "contactos" del joven Joaquín Nebra (su padre y hermano Francisco Javier, y acaso también su hermano mayor, José, entonces ya bien conocido en la corte, más su pariente José Diego Lacarra, capitular en La Seo), hubieran podido jugar sus bazas a la hora de "recomendar" y avalar a su familiar para cubrir

50. La presencia de estos "infanticos" apellidados «Moreno y Polo» aparece muy frecuentemente entre la documentación de la época en las catedrales zaragozanas, así como también se refleja en numerosos "graffittis" dejados por los niños Moreno, que anotaban sus nombres y dejaban constancia de haber cantado determinadas composiciones (con "esperanzas" de seguir haciéndolo en años sucesivos si conservaban la voz todavía sin mudar) en muchos cantorales y libros de polifonía. Así por ejemplo sucede en el símbolo atanasiano «Quicumque» del compositor Urbán de Vargas, maestro de capilla en El Pilar a mediados del siglo xvir. Ello nos da muestra de que los hermanos «Moreno y Polo» participaban, y se contaba con ellos, para ejecutar algunas de las partes principales o protagonistas en ciertas versiones policorales destacadas - síntoma de su pericia técnica-, lo que se vería más tarde refrendado por los cargos que, ya de adultos, llegarían a ocupar estos hermanos músicos (José, tercer organista en la Real Capilla; Valero, maestro de capilla de la catedral de Tortosa - Tarragona-; y el propio Juan, que desempeñaría largos años la organistía de la seo tortosina).

51. La iglesia de San Pablo, aparte su importancia histórica desde época medieval, cuenta con una fábrica de dimensiones catedralicias y dispone de un órgano verdaderamente excepcional, que le han valido ser considerada como la tercera catedral zaragozana. Por su parte, la iglesia del Portillo, era una de las parroquias entonces más pujantes de la ciudad, cuyo ascenso culminaría años más tarde con el importante papel que hubo de desempeñar como bastión defensivo contra los franceses -en el que se destacó la célebre Agustina de Aragón - durante la Guerra de la Independencia.

52. Así al menos podría desprenderse de la gratificación que a la marcha de Valero Moreno le concedió el cabildo de La Seo zaragozana, o los favorables informes que sobre él dieron al cabildo tortosino el maestro de capilla de La Seo (José Lanuza) y el organista de El Pilar (Tomás Soriano), con quienes se habría formado como niño cantor, los cuales informes sirvieron para que el capítulo tortosino le nombrara como su nuevo maestro de capilla, por unanimidad. 
la vacante dejada. Sin duda, buena parte de los miembros del capítulo de La Seo conocerían bien a los distintos músicos de la familia Nebra y su excelente reputación profesional.

En todo caso, al dejar entrar a los mejores cuatro aspirantes en la votación (Subías, Sierra, Moreno y Nebra, — de los cuales Joaquín Nebra sólo había sido el último técnicamente-), se diversificaba la oferta, facilitándose así el poder contar con candidatos muy jóvenes (Juan Moreno y el propio Joaquín Nebra), aunque de ascendencia solvente, a quienes poder "moldear". Se podrían tener así además en consideración otros factores (de proximidad, moralidad y buena conducta, inclinación a la crianza de los infantes...), y no solamente los específicamente musicales. En este sentido, a pesar de su juventud, la balanza se inclinaba claramente del lado del joven Nebra, hermano menor del organista saliente.

Pero, aparte de las hipótesis que pudieran plantearse, analicemos ahora brevemente cómo se desenvolvió Joaquín Nebra durante las oposiciones. Ya hemos visto cómo quedó calificado tres veces en primer lugar, siete en segundo, seis en tercero, dos en cuarto, dos en quinto, y en cinco ocasiones quedó sin grado.

Parece lógico que entre tantos candidatos a la plaza (siete), hubiera unas primeras pruebas "de tanteo", con vistas a familiarizarse entre examinadores y opositores. De hecho, Nebra, que se llevó más tarde la plaza, no destacó precisamente durante los primeros días de exámenes, sino más bien hacia el final de los ejercicios. Por otro lado, de las tres ocasiones en que Joaquín Nebra alcanzó el primer lugar, en ninguna de ellas lo hizo en solitario. Parece en este sentido que su valoración fue mejorando según avanzaba el proceso de la oposición, pues únicamente obtuvo el primer lugar al término del penúltimo día (en el penúltimo ejercicio que se les pidió), y en las otras dos ocasiones obtuvo el primer puesto en el último día (concretamente en el último caso, logró la mejor calificación en el penúltimo ejercicio de la oposición).

De modo que, un aspirante como él, que no había destacado particularmente al principio, sólo hacia el final de la oposición consiguió una cierta consideración técnica. Y no lo hizo en la modalidad de la composición, o en la de los pasos y fugas más complejos, sino en la propiamente de la ejecución instrumental, es decir, en tocar: acompañar unos versos por unos tonos determinados (octavo tono y segundillo), tocar asimismo por un tono transportado (sexto tono punto bajo), y tañer música "cromática".

Es decir, que Nebra destacaba por ser un hábil "pulsador" individual ante el teclado, habituado a manejarse por las distintas tonalidades y que dominaba sus secretos más "mecánicos". De este modo, se mostraba "útil" para el servicio del culto, pues, con sólo veinte años, ya se destacaba frente al resto como perito a la hora de seguir un tono determinado. Igualmente, quedó dos veces en segundo lugar cuando hubo de tañer versos sobre temas gregorianos dados (sobre el "Ave maris stella", y sobre el "Pange lingua", respectivamente), lo que parece ratificar una más que posible costumbre (acaso adquirida de su padre y hermanos mayores) de improvisar o remedar al teclado melodías "tradicionales" a los oídos de cualquier organista de la época. Y por otro lado, en dos ocasiones quedó en segunda posición a la hora de "tañer de su elección", lo que sugiere que, aunque muy joven todavía, tendría ya buen gusto, y acaso una mayor buena disposición, que no tanto preparación técnica propiamente dicha. 
En contrapartida, al no haber hecho "nada", quedó sin grado a la hora de desarrollar unos contrapuntos, al tañer un intento tras haberse cantado un Kyrie, o al tener que acompañar un villancico, una tonada, o un Magnificat. Esto quiere decir que, posiblemente debido a su juventud, resultaba todavía poco despierto en los ejercicios que requerían mayor capacidad mental o imaginativa (contrapunto, tientos..., obras en lengua romance - por lo general más "progresistas"-...), así como en la compenetración a la hora del trabajo camerístico o la ejecución con otros intérpretes (acompañamiento). En este sentido, podríamos decir que todavía estaba falto de cierta "escuela", pues también quedó en la última posición a la hora de realizar unas cadencias o cláusulas en un tono transportado concreto (séptimo tono punto alto).

Pero, en puridad, considerar lo anterior como característica de lo que iba a ser después la actividad de Joaquín Nebra al frente de la organistía de La Seo podría ser ciertamente distorsionador: no se debería juzgar la labor de un organista que desempeñó con competencia su cargo más de medio siglo, por unos ejercicios "de juventud"; aunque, por otro lado, no hemos de perder de vista la complejidad de los mismos, y que un organista podía entonces considerarse plenamente formado a la temprana edad en que aquí compitió Joaquín Nebra. De hecho, él, como otros muchos músicos que ganaban sus plazas una vez se posesionaban de ellas, podría haber adquirido mayor formación "a posteriori", si ése hubiera sido el camino hacia el que le encaminaran sus propias inquietudes; pero ya no estaría "obligado" a ello, como hasta entonces, para garantizarse el sustento. Sin duda, él, como muchos otros en una situación similar a la suya, iba a adquirir mucha más experiencia, pero, su formación técnica, como tal, había finalizado. Y por tanto, son muy significativos los datos que este tipo de ejercicios nos sugieren: para los 19 (Juan Moreno) ó 20 años (Joaquín Nebra), un organista de la época poseía ya una formación versátil y más o menos acabada. Pero distaba mucho de ser experimentada y técnicamente sólida. Frente a factores hoy en día altamente considerados en la formación de un músico, como el conocimiento profundo de las reglas de la armonía, el contrapunto y la composición (que también se poseían, y en alto grado, en la época), acaso en virtud de la rapidez e intensidad del período de aprendizaje, parece ser que primaba entonces la utilidad o funcionalidad que pudiera aportar el músico a su patrón (aquí, su cabildo catedralicio), así como su "creatividad", frescura de ideas, originalidad (a veces traducida más bien en clave de ingenuidad), y capacidad de adaptación a las situaciones más diversas (acompañar, improvisar, componer, repentizar sobre un tema dado, cadenciar...).

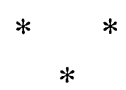

Repasado el papel de Joaquín Nebra en las oposiciones del año 1730, excluiré aquí las informaciones ulteriores (procedentes de las actas capitulares, fundamentalmente) ya dadas a conocer a propósito de sus años de titularidad al frente del órgano de La Seo zaragozana ${ }^{53}$. Repa-

53. -Dionisio Preciado Ruiz de Alegría: "Joaquín Nebra (1709-1782). 52 años largos...”, op. cit., 1977, pp. 1217. -ID.: "Joaquín Nebra (1709-1782). 52 años largos...", op. cit., 1977, pp. 40-45. -ID.: Doce Compositores..., op. cit., 1983. -José Vicente GonzÁlez Valle: Siete Palabras de Cristo en la Cruz. Barcelona, CSic, "Monumentos de la Música Española, LXI", 2000, pp. 19-51. 
saré no obstante, por su especificidad y conexión directa con el tema de este artículo, y únicamente con la intención de recopilar en un mismo listado los datos referidos a Joaquín Nebra posteriores a 1750, los datos ya dados a conocer por José V. González (Actas Capitulares de las catedrales de Zaragoza, ejemplar de La Seo, manuscrito) $)^{54}$ :

-Año 1753:

Fol. 20. [Entrada $N^{\circ}$ 109]. [Joaquín Nebra, Organista de La Seo, suplica aumento de salario]

"Se leyó memorial de D. Joaquín Nebra, Organista del Santo Templo del Salvador, en el que, exponiendo al Cabildo hallarse con el trabajo de haber fallecido sus padres y hermano, que en otro tiempo mereció el honor de servir al Cabildo, y ahora verse con la precisa obligación de asistir a su familia, recurre a la piedad del Cabildo para que se le considere aquel aumento de salario que pareciese más digno. Se acordó votarse para cajuelas, y quedó resuelto que no ha lugar a su petición" 55 .

-Año 1760:

Fol. 70.

“Organista [Joaquín] Nebra en Madrid. Va a Madrid a ver a su hermano. Deja sustituto".

\section{-22-VIII-1766:}

[Entrada $\mathrm{N}^{\circ}$ 221]. [Joaquín Nebra, Organista $1^{\circ}$ de La Seo]

"Se leyó un memorial de D. Bernardo Miralles en que pide compañeros para el examen de las obras que han trabajado los pretendientes del Magisterio del Pilar, a [Tomás] Soriano [Organista del Pilar] y Nebra; y se concedió como lo pide".

54. Datos publicados en: -José Vicente González VAlle: Siete Palabras de Cristo..., op. cit., 2000, pp. 19-51.

55. Comenzamos aquí a ver las dificultades económicas por las que debía pasar la familia Nebra, toda vez que el hermano músico, Francisco Javier, había fallecido tempranamente en Cuenca en 1741 (dejaba esposa - Juana Vieco-, y una hija, Ignacia), y el padre de la dinastía, José Antonio, lo había hecho en 1748 (dejaba esposa, Rosa Blasco, y a su hija María Ana -o Mariana-). La existencia de una familia abultada a la que apoyar económicamente tan sólo contaba, al parecer, con el apoyo financiero de los dos músicos para entonces en activo de la familia, José [Melchor] Nebra (en la corte), y Joaquín Nebra [en la catedral de Zaragoza], como así se desprende de diversos documentos conservados. [Véase: -Ma Salud ÁLVAREZ MartíneZ: José de Nebra Blasco. Vida..., op. cit., 1993. Cfr. pp. 41 y 192-193]. Se trata de la licencia para testar de los padres José Antonio Nebra y Rosa Blasco, a favor de sus hijos José Melchor, y Joaquín (1747). Se dice ahí que “... conociendo [los padres] que para su manutenzion y dezencia de estas [herencias] no nezesitan [se refieren a José Melchor y a Joaquín], por tener bastante renta para ello, y que los bienes que tengan los expresados don Joseph, y don Joachin, los han granjeado con su habilidad, sin interbencion de los otorgantes [es decir, de sus padres], pues antes bien los han asistido, y a los demas sus hermanos con el mayor amor, y mejor correspondencia; por lo qual, y hazerles bien y merzed a los referidos nuestros hijos, y en atencion a lo que como tales nos han favorecido [...]". Téngase en cuenta que José Melchor, era soltero, y que Joaquín, aunque casado (con María Redonet), no tuvo descendencia. Por otra parte, entre los familiares residentes en Cuenca, se contaba la hermana menor de los músicos bilbilitanos, que había nacido ya en la ciudad castellana, María Ana, y también la hija de Francisco Javier, Ignacia, ambas monjas profesas en el conquense convento de San Pedro. El mismo día en que sus padres les concedían licencia para testar (7-VIII-1747), José Melchor, y Joaquín, renunciaban a la herencia paterna en favor de su hermana menor, María Ana, y su sobrina, Ignacia. [Además de los ya mencionados, José Melchor debió tener también a su cargo, a su sobrino sevillano, Manuel Blasco, quien residía en su casa de Madrid, y no sabemos hasta qué punto tal vez también a su sobrina sevillana, Vicenta Blasco, quienes actuaron el 9-vII-1768 como albaceas testamentarios en las últimas voluntades del célebre músico activo en la corte. Vid.: -Ma Salud Álvarez Martínez: José de Nebra Blasco. Vida..., op. cit., 1993, p. 231]. 
-Año 1772:

[Entrada $N^{\circ} 207$ ]

"Joaquín Nebra, Organista, protesta que no le han pagado los entierros. El Cabildo hace saber que el Organista tiene su silla en el órgano, y por lo tanto, presencia, y se le debe pagar".

$-26-I V-1776:$

Fol. 47.

"Se leyó memorial de D. Joaquín Nebra, Organista de La Seo, en que, en atención a sus servicios, pide que el Cabildo se sirva concederle la casa en que vivió Dn. Pedro Benedid, y está cerrada, para habitarla durante la voluntad del Cabildo sin pagar arriendo. El Cabildo se la concede, pidiéndole que cierre la ventana que da a la capilla de San Valero, y que la Fábrica la repare y haga habitable. Lo que no impide que tenga que dejarla si el Cabildo determina derribarla".

$-7-1 X-1780$ :

Fol. 100.

"Se leyó otro memorial de Francisco Xavier García, Maestro de Capilla del Santo Templo del Salvador, que expone que D. Joaquín Nebra, Primer Organista de La Seo, hace cincuenta años que sirve su empleo, con la aplicación y destreza que es notorio; pero en el día no está para desempeñarlo, y mucho menos en los días de mayor solemnidad, y por su ancianidad y accidentes; en cuyas circunstancias, si Joaquín Laseca, $2^{\circ}$ Organista, sale a las oposiciones que concurran en solicitud de un acomodo, no hay quien pueda desempeñar este empleo. Que en el mismo, concurren la aplicación y habilidad, así en la composición de música como en el desempeño del órgano y acompañamiento, y los méritos de haber servido a la Iglesia trece años, siete de Infante y seis de $2^{\circ}$ Organista, habiendo acreditado en ellos su buena conducta e inocentes costumbres. Por todo [...], suplica se le conceda a dicho Laseca la futura del órgano, que se ofrece servir sin renta alguna durante la vida de Joaquín Nebra, quedando así premiados los méritos de ambos, y asegurando un ministro, que con dificultad podrá mejorarse para el servicio de la iglesia y el Cabildo [...]; reflexionado todo [...], se concedió la futura del Primer Organista del Santo Templo del Salvador al referido Joaquín Laseca, con el salario que tendrá a bien señalarle, cuando llegue el caso de entrar en el goce de su empleo; y se acordó que D. Joaquín Nebra continúe siempre con el nombre y exercicio en cuanto pudiere de Primer Organista, y con toda la renta y emolumentos, que como a tal le pertenecen durante su vida, sin la menor disminución".

\section{-23-VIII-1782:}

[Entrada $N^{\circ}$ 197]. [Joaquín Nebra, Organista $1^{\circ}$ de La Seo, muerte]

"Se leyó memorial de D.n Joaquín Laseca, Organista $2^{\circ}$ de La Seo; pide al Cabildo, haciendo presente la muerte de [Joaquín] Nebra, Organista $1^{\circ}$, y la resolución del Cabildo del 15 de Noviembre de 1780, concediendo la futura de esta plaza a Joaquín Laseca. El Cabildo adjudicó a Laseca la plaza de Organista principal de La Seo, con la obligación de ir a enseñar a los infantes a su casa, o éstos pasar a la suya". 


\section{-23-VIII-1782:}

[Entrada $\mathrm{N}^{\circ}$ 198]. [Viuda de Nebra, Organista $1^{\circ}$ de La Seo, difunto]

“Doña María Redoné, viuda de D. Joaquín Nebra, pide ayuda en recuerdo de su marido. El Cabildo la socorre en memoria de los largos servicios y distinguidos méritos del difunto".

\section{-30-VIII-1782:}

[Entrada $N^{\circ} 204$ ]. [Viuda de Nebra, Organista $1^{\circ}$ de La Seo, difunto]

"Se habían visto en Junta de Hacienda los memoriales de D. Joaquín Laseca, Organista $2^{\circ}$ de La Seo, con el tanto de renta que tenía D. Joaquín Nebra, Organista $1^{\circ}$ del mismo Templo, y el memorial que Dña. María Redoné, Viuda de Nebra; se le había concedido a Laseca la futura de esta plaza; se asigna a la viuda $5 \mathrm{~s}$. diarios, y la casa, con la condición de vivir en ella, y esto por los particulares servicios de su marido y dilatado tiempo que ha servido a la iglesia, con la ley y amor que es notorio; se aprobó en el Cabildo lo que la Junta acordó”.

-29-XI-1782:

[Entrada $N^{\circ} 317$ ]. [Papeles de música de Joaquín Nebra]

"Los papeles de música del Organista Nebra se retienen. Los papeles de música que dejó el Organista Nebra en poder de su mujer, valuados en 30 pesos, hay quien intenta llevárselos a reino extraño, y que son muy útiles para la iglesia; se acordó de que se retengan y archiven, para si el Organista quiere copiar alguno de ellos, y que lo pague la Fábrica su valor”.

\section{-24-I-1789:}

Fol. 3. [Viuda de Nebra, Organista de La Seo]

"Memorial de Quiteria Freile; pide ayuda para pagar el entierro de la viuda de Joaquín Nebra, Organista de La Seo".

Del largo período durante el cual Joaquín Nebra sirvió como organista de La Seo de Zaragoza (1729-1782), contamos con algunas noticias sobre las actuaciones de reparación, mejora, afinación o ampliación del instrumento a su cargo, y así por ejemplo, podemos mencionar los trabajos realizados por el maestro organero Silvestre Thomás en los años 1748, 1755 , y $1758^{56}$. El cargo de Joaquín Nebra, como vimos, le permitía, si no esplendideces, sí al menos cierto desahogo económico, que le capacitaba para no precisar del apoyo familiar y, antes al contrario, poder ayudar a algunos parientes. Podemos entretanto apreciar un detalle de sus

56. Vid. «Libros de Fábrica» de La Seo, correspondientes a los años mencionados. 
ingresos correspondiente al año $1764^{57}$, según documentación conservada en los archivos zaragozanos $^{58}$ :

"Nebra Org. ${ }^{\text {ta }}$ Raz. ${ }^{\text {n }}$ Supresa de d. ${ }^{\text {n }}$ Lope.

Por dobles en Canonical...

$\begin{array}{lll}£ & 8412 \mathrm{~s} 6 \mathrm{~d} & / \\ £ & 5415 \mathrm{~s} & / \\ £ & 36 & / \\ £ & 2210 \mathrm{~s} & / \\ £ & 19717 \mathrm{~s} 6 \mathrm{~d}\end{array}$

Por distribuciones en Aniversarios...

Por 6 Coquetas diarias...

Por Vestuario en Canonical...

[Total:]

[Tenor $1^{\circ}$. Vacante...] [...]

[Tenor $2^{\circ}$. Navarro. Mendiondo...] [...]

[Contralto $1^{\circ}$. Lloscos...] [...]

[Contralto $2^{\circ}$. Lobaco...] [...]

[Vajon $1^{\circ}$. Vela...] [...]

[Vajon $2^{\circ}$. Villanueva...] [...]

[Violin $1^{\circ}$. Domini...] [...]

[Violin $2^{\circ}$. Cheroni...] [...]

[Arpista Serrano...] [...]

[Sorchantres...] [...]

$\left[2^{\circ}\right.$ Maestro...] [...]

$\left[3^{\circ} \ldots\right][\ldots]$

[Quarto...] [...]

".

Vemos cómo el maestro de capilla cobraba su salario por una partida diferente, sin duda aparte del resto de los músicos; cómo se contabilizaban hasta cuatro maestros en La Seo; y cómo el organista y racionero Joaquín Nebra cobraba su sueldo, como era habitual, por diferentes conceptos (su salario "base", más otras partidas extraordinarias — vestuario, reparto por asistencia en aniversarios...-). De estas últimas, todavía puedo aportar un detalle más ${ }^{59}$ :

"Nebra Organista.

En Aniversarios...

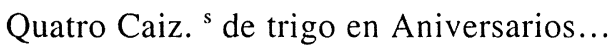

$\begin{array}{ll}£ & 36 \\ £ & 16 \\ £ & 20 \\ £ & 72\end{array}$

[Total:]

[Contralto $1^{\circ}$ Lobaco. ] [...]

[Vajon $1^{\circ}$ Vela. ] [...]

[Vajon $2^{\circ}$ Villanueva] [...]

[Violin $1^{\circ}$ Domini. ] [...]

1
1
1
1
1
1
1
1
1

57. Según un documento del archivo catedralicio zaragozano, consta que eran «Músicos de la capilla de La Seo en 1760» -es decir, "en plantilla"-, los siguientes: "Organista $1^{\circ}$ y $2^{\circ}$ y entonador; violón (Campillo): $1^{\circ}$ y $2^{\circ}$ bajón; Gutiérrez; Lloscos; José Sagardivelz (Tiple); $1^{\circ}$ violín (Donini); $2^{\circ}$ violín; dos sochantres (Ortiz y Salas); infantes (Diarte, Jorro, Molina y Morcalé); maestro de capilla".

58. "Razon de lo q. " la Bolsa de Aniv." emplea en Musicos, y Sorchantres, para descar= I de su obligacion, y de los sugetos, que lo perciben. año $1764 \%$.

59. "Gracias â Musicos y Sorchantres.». 
[Espurz Sorchantre $\left.1^{\circ}\right][\ldots]$

[Blasco Sorchantre Jubilado] [...] /

[Plaza Sorchantre Jubilado] [...]

[Asignò el Cav. do â Antonio Zintora] [...] /

Suma la renta efectiva de la prim. a plana /

que debe emplearse en Musicos, y Sorchantres... $\quad £ 1538$ 12s 6d /

Descargo

Reciven los Musicos, y Sorch. ${ }^{\mathrm{s}} \ldots$

Reciven los mismos por gra. ${ }^{\mathrm{s}} \ldots$

[Total:]

Quedan â beneficio de la Bolsa de Anivers. s...

Se aumentan el importe de las seis coquetas del

Sacristan maior $\mathrm{q} \sim$ son de las correspondientes

à sacristia...

[Total:]

$£ 115013 \mathrm{~s} 8 \mathrm{~d} \quad /$

$£ 37714 \mathrm{~s} \quad /$

$£ 1528 \quad 7 \mathrm{~s} 8 \mathrm{~d} \quad /$

$£ \quad 10 \quad 5 \mathrm{~s} 5 \mathrm{~d} \quad /$

1

$£ \quad 36 \quad 1$

$£ \quad 46$ 5s $5 \mathrm{~d} \quad / ”$.

Es decir, que (aparte calderilla en sueldos y dineros), cobraba casi doscientas libras jaquesas (!), más otras setenta y dos por otros diversos conceptos ${ }^{60}$. Una cantidad nada despreciable para la época, - a pesar del enorme trabajo que le debía reportar el desempeño de su cargo-, la cual, sin duda, le llevó a rechazar otras ofertas para cambiar el destino de su plaza, como así sucedió en el caso de la Catedral de Cuenca ${ }^{61}$.

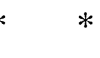

$*$

En cuanto a la presencia concreta de José Nebra Blasco ${ }^{62}$ en las catedrales zaragozanas, anoto a continuación las obras que de él se conservan en el archivo de música (ocho obras, más un impreso de la segunda mitad del siglo XIX y tres obras atribuidas):

60. Según otra documentación capitular, en 1773 el organista de La Seo cobraba solamente £130 de renta, más otras $£ 20$ de aumento. Acaso por esto, registramos en las actas capitulares que el año anterior, 1772, Joaquín Nebra protestaba que no se le habían pagado "los entierros"... La cuestión económica debía empeorar paulatinamente, de modo que los músicos activos en torno a las catedrales trataban de asegurarse su manutención, y su futuro: en 1780, el maestro de capilla de La Seo, Francisco Javier García Fajer, "el Españoleto", pide ya que el cabildo concediera "la futura" al joven Joaquín Laseca, discípulo suyo, que hacía las veces de suplente u organista segundo, dados los achaques del ya anciano organista titular, Joaquín Nebra. De hecho, se pedía ya reservarle la plaza para cuando Nebra falleciera, aún estando éste vivo todavía...

61. Véase: -Miguel Martínez Millán: Historia musical de la Catedral de Cuenca..., op. cit., 1988, pp. 148-149.

62. José Nebra fue organista de las Descalzas Reales de Madrid cuando aún tenía 15 años (!). Desde los 20 colaboró en las "academias" de los salones de la Casa de Osuna. Maestro de José Lidón, Francisco de Anaya o Joaquín Oxinaga, recomendó a su sobrino José Calanda $(\uparrow 1780)$ para la organistía de la Catedral de El Burgo de Osma. Fue miembro (segundo clave, tras Nicolás Conforto) de la orquesta de ópera del Coliseo del Buen Retiro, bajo coordinación de Farinelli. Organista de la Real Capilla durante 44 años, supervisó la reparación y construcción de varios órganos en Madrid (San Jerónimo, capilla del Palacio Real), y se responsabilizó de crear un nuevo archivo musical para la Real Capilla, tras el incendio de 1734. Coincidió con Francisco Corselli, Nicolás Conforto, Francisco Coradini, Antonio Duni, Mele, Inachi... Colaborador de compañías teatrales españolas durante casi 30 años, fue el mejor compositor de obras escénicas entre 1740 y 1750 . Trabajó con libretistas como N. González Martínez, Antonio Merano, Armesto Quiroga, Fernández de Bustamante, Antonio Zamora, Reinoso, Antonio Flores, o José de Cañizares. Elogió la obra de José de Torres (tal vez su maestro), de Alessandro Scarlatti,

Anuario Musical, 57 (2002) 
1) - «Joseph de Nebra». Vísperas de facistol, a cuatro voces (S, A, T, B), [1759]. Un libro manuscrito de $21 \times 28 \mathrm{~cm}$., encuadernado con tapas de piel y decoración repujada en oro -en tapa, lomo y contratapa-, la cual inserta el escudo real de los borbones en tapa y contratapa. El interior de las tapas se protege con papel de aguas florentino. Procede de la Capilla Real. 103 páginas. Está foliado a lápiz, del 0 (página de título) al 51, con dos folios previos en blanco, y otros dos al final - uno pautado, en blanco, y el segundo totalmente en blanco-. Signatura moderna: E: Zac, LS-18 (1 a 10) [N 271 del antiguo inventario; otra signatura antigua: «N 129»]. Constan de los siguientes salmos: -Dixit Dominus ( $1^{\circ}$ tono); -Beatus vir ( $3^{\circ}$ tono); -In exitu Israel (tono peregrino); -Credidi propter (4º tono); -Laudate Dominum ( $3^{\circ}$ tono); -Laetatus sum ( $5^{\circ}$ tono); -Memento Domine ( $3^{\circ}$ tono); -Domine probastime $\left(2^{\circ}\right.$ tono); -Lauda Jerusalem $\left(7^{\circ}\right.$ tono); y -[Cántico] Magnificat ( $8^{\circ}$ tono).

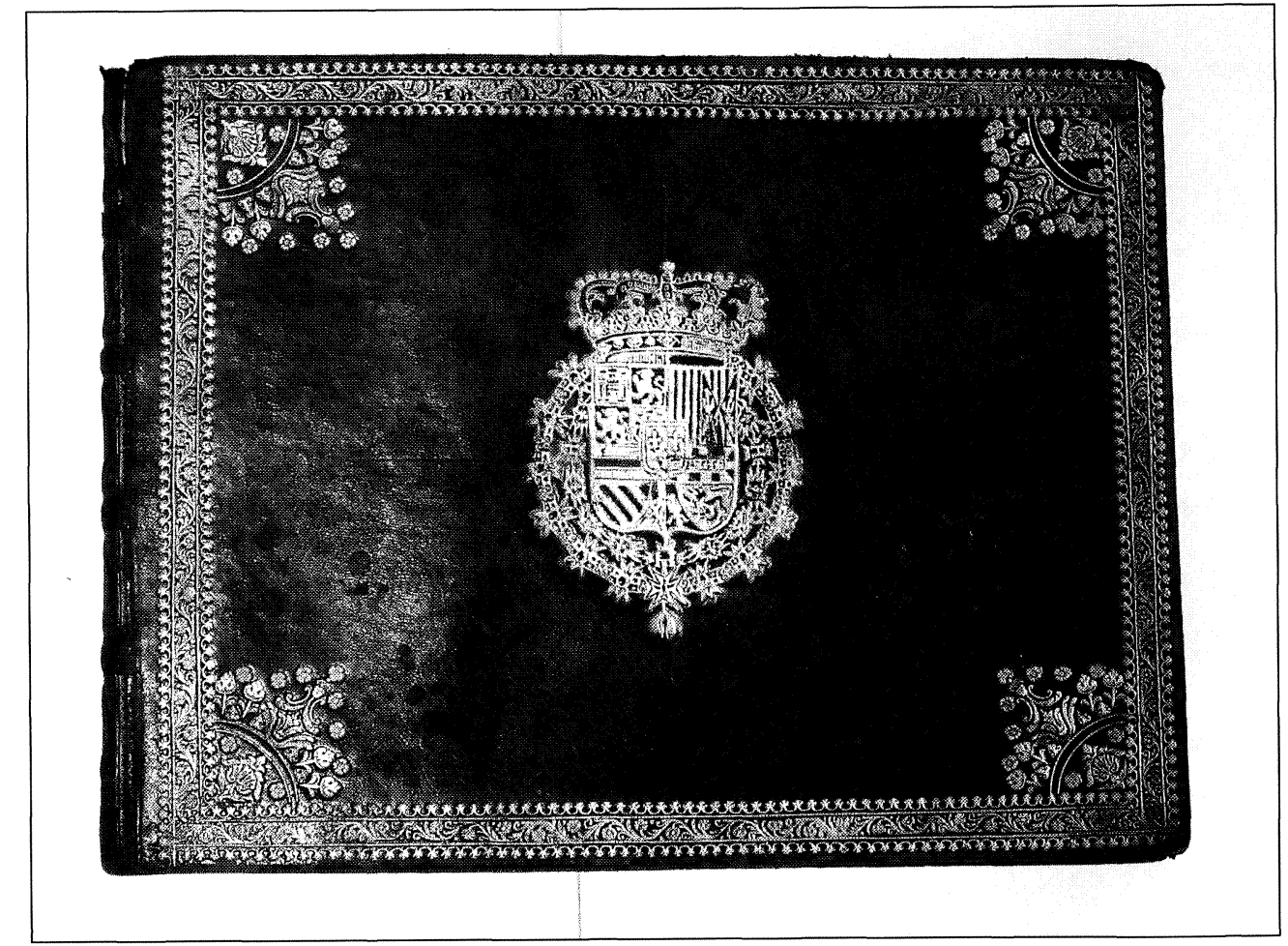

Figura 18

«Vísperas de facistol», a 4 voces, (tapa del volumen manuscrito) de «Joseph de Nebra» Archivo de Música de las Catedrales de Zaragoza [E: Zac, LS-18 (1 a 10)]

\footnotetext{
Leonardo Leo, Domenico Sarro, Miguel de Ambiela, Francisco Valls..., y fue buen amigo de José Elías. Trabajó, para la escena, comedias de santos, autos sacramentales, etc. En 1761, Carlos III le nombró maestro de clavicordio del infante Don Gabriel. Coetáneo de Antonio Ripa, Jaime Casellas, o José Mir, falleció a los 66 años.
} 


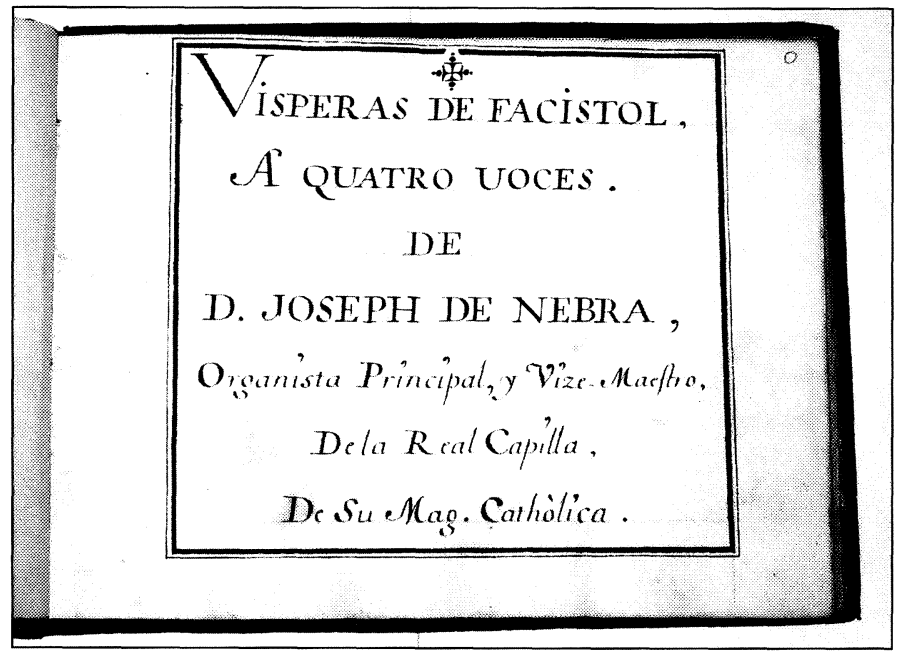

Figura 19

«Vísperas de facistol», a 4 voces, (portadilla) de «Joseph de Nebra». Archivo de Música de las Catedrales de Zaragoza [E: Zac, LS-18 (1 a 10)]

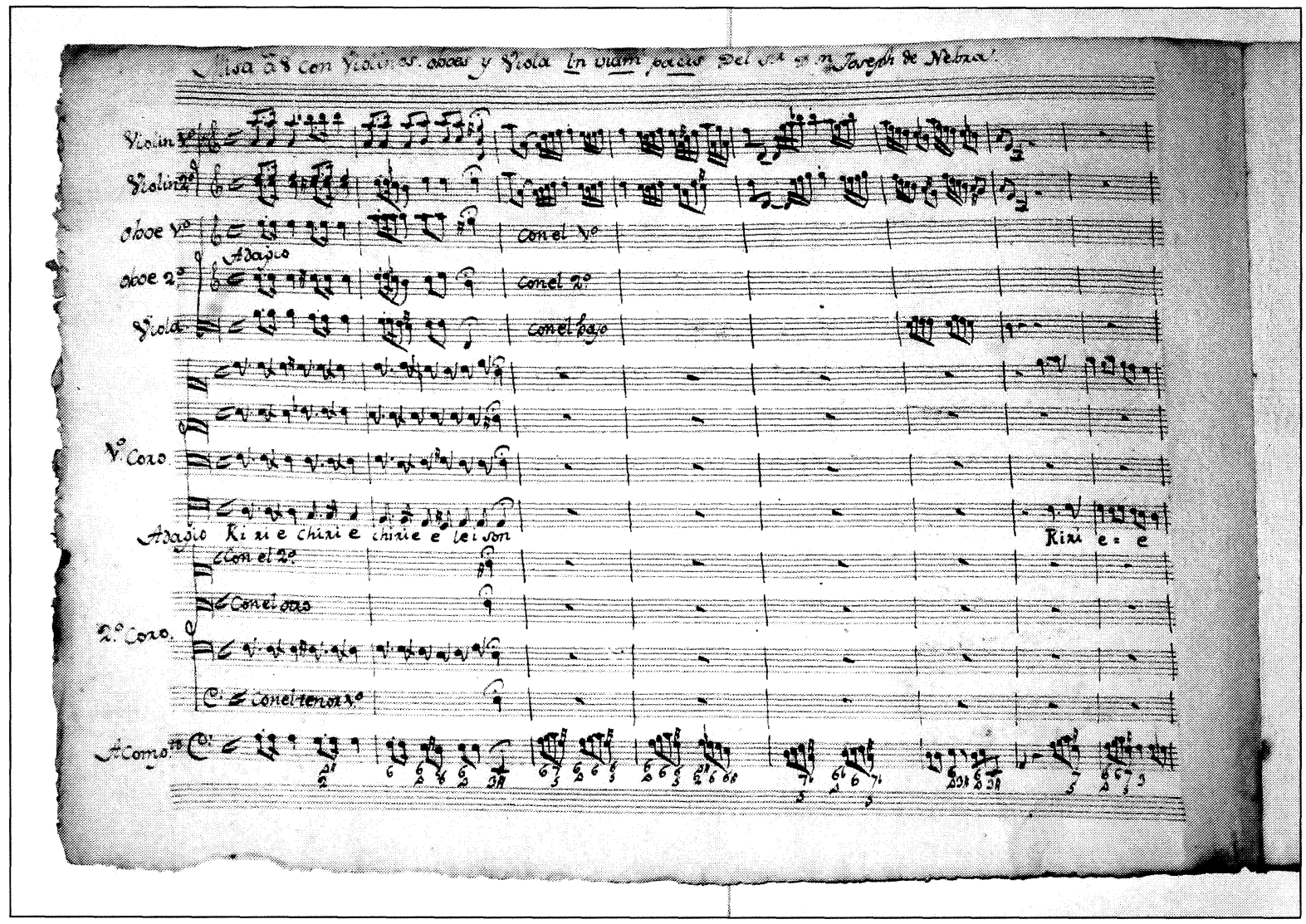

Figura 20

«Misa ã 8 con Violines. oboes y Viola In viam pacis Del S.r I.n Joseph de Nebra» Archivo de Música de las Catedrales de Zaragoza $[E: Z a c, \mathrm{~s} / \mathrm{s}]$ 
2) - «Joseph Nevra». Un libro manuscrito, con tapas de pergamino, que incluye un salmo Dixit Dominus [1750; a 8, con violines, trompas, oboes y acompañamiento], y una Missa [«Laudate Dominum de terra», 1748].

3) - «Joseph Nebra». Un libro con el salmo Miserere, a dúo, con violín y viola. (S 1, 2; vl 1, 2, vla; acompto.)

4) - «Joseph de Nebra». Missa «In viam pacis», a 8, con violines, oboes y viola [1748].

5) - «Joseph Nebra». Misa, a 8. con Violin. s Clarin y Viola, Sobre el Pangelingua [In Coena Domini]. Escrita para: Coro 1: S 1, 2, A, T; Coro 2: S, A, T, B; vl 1, 2, vla; ob 1, 2; clno [sobrepuesto]; acompañamiento. fig (1747).

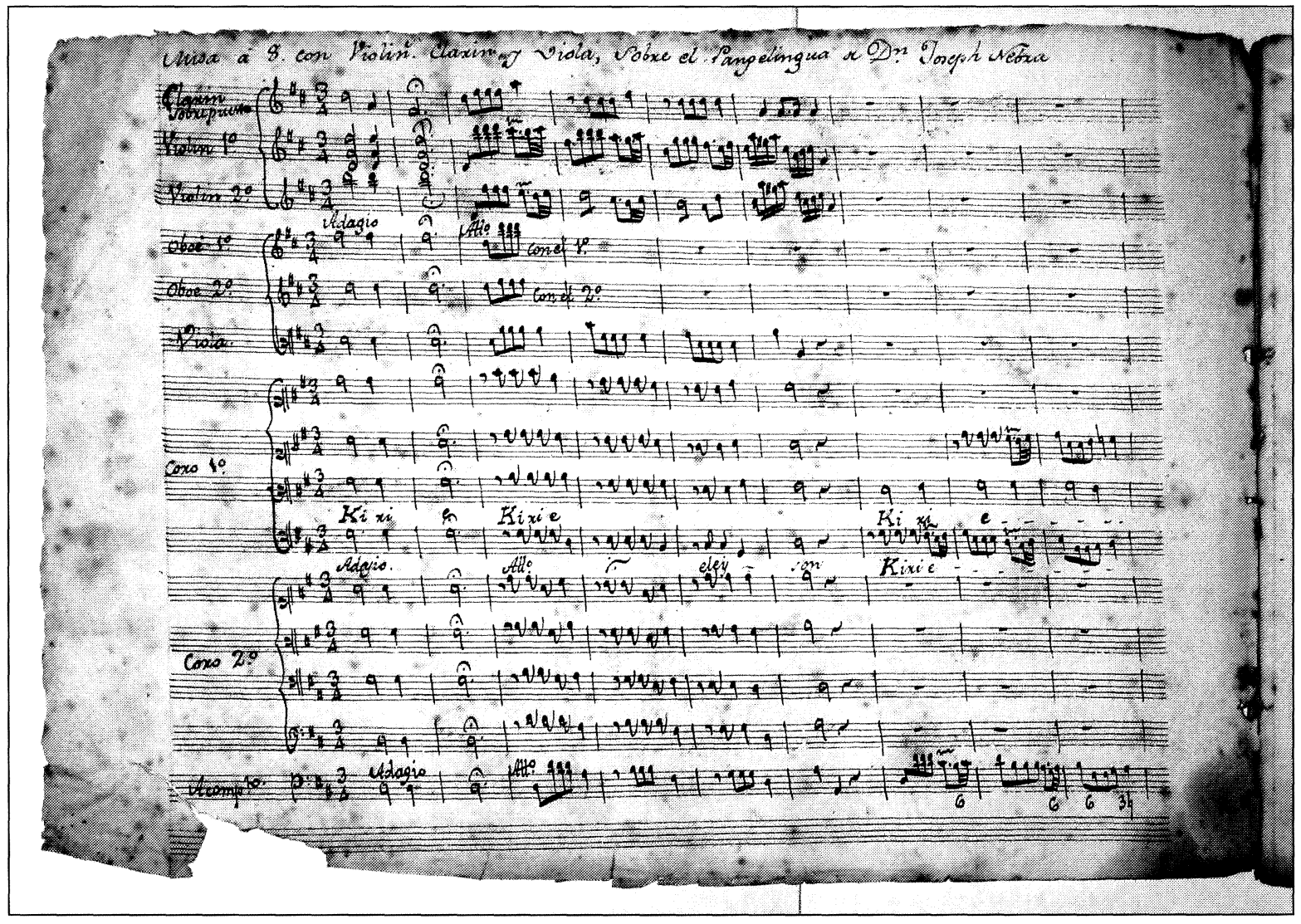

Figura 21

«Misa, ã 8. con Violin. s Clarin y Viola, Sobre el Pangelingua de D.n Joseph Nebra» Archivo de Música de las Catedrales de Zaragoza [E: Zac, s/s]

6) - Un libro manuscrito con música de tecla [sonatas] (signatura: E: Zac, B-2 s/n), formado por diversos cuadernillos cosidos con pastas de papel, de $34,5 \times 24 \mathrm{~cm}$. (1750c). Consta de 36 folios numerados a lápiz, sirviendo el primero y el último de tapas. La música comienza en el fol. 2r. Incluye, a modo de "repertorio", numerosas obras anónimas, y otras de Domenico Scar- 
latti. La última pieza, muy posiblemente sea obra de José Nebra, como, acaso, algunas otras piezas anónimas del volumen. Sin embargo, no queda claro si el contenido del libro es obra en su conjunto de José Nebra (salvo las piezas anotadas como de Domenico Scarlatti), o si, más posiblemente, se trata únicamente de un libro de su propiedad, para su uso personal («Estas de Escarlati, las podra el S.r D.n Joseph tocar donde gustare»). (Véase Figura 24). En cualquier caso, el libro (acaso anotado por algún copista para el uso del citado José Nebra) está rubricado por él. En cualquier caso, también es posible que él mismo hubiera copiado para sí algunos de los cuadernillos que componen el volumen. Al final del último folio con música - fol. $35 \mathrm{v}$ - , a modo de explicit, se anota - y viene rubricado- lo siguiente: «Obra del S.r D.n Joseph Nebra». (Véase Figura 25).¿Se refiere esta anotación a la autoría de esta última pieza?, ¿a todo el libro?, ¿solamente al último cuadernillo cosido?, o bien ¿quiere decir que José Nebra es simplemente el propietario?, o ¿podría haber sido propietario y copista a un tiempo? Responder a estas cuestiones necesitaría de un detenido análisis paleográfico y estilístico, que escapa de las intenciones de este artículo ${ }^{63}$. En todo caso, lo cierto es que las diferentes piezas están escritas "de corrido", sin separaciones, de modo que en varias ocasiones es difícil discernir si se trata de una pieza independiente, o si es un segundo o tercer movimiento de la pieza anterior, incluso atendiendo a la tonalidad o a los motivos melódicos. Tómese por tanto con cautela la numeración que aquí se sugiere. El libro, interesantísimo por el contenido que recoge (obras de D. Scarlatti anotadas en la época, otras posiblemente de José Nebra, más una gran parte anónimas, pendientes de identificar), refleja lo siguiente:

1) - [Fols. 2r al 5r]. Fol. 2r: [encabezamiento:] «J. M. Y. J. 1 Sinfonia de la [?] Nra. Sa Del Carmen me asista». Re Mayor $\phi$ Allegro; Fol. 4r: (2 movimiento:) Re menor 6/8 Cantabile; Fol. 4v: ( $3^{\circ}$ movimiento:) Re Mayor 3/8 Allegro.

2) - [Fols. 5r al 10v]. Fol. 5r: [encabezamiento:] «J. M. Y. J.». Sol Mayor $\phi$; Fol. 9r: «Correnda». Mi menor 3/4 Vivo; Fol. 10r: Mi menor 6/8 Vivo. [Fol. 11r, en blanco].

3) - [Fols. 11v al 14v]. Fol. 11v: Do menor C; Fol. 12v: (2 movimiento:) Mi bemol Mayor 3/8; Fol. 13v: ( $3^{\circ}$ movimiento): Do menor 12/8.

4) - [Fols. 15r al 20v]. Fol. 15r: La Mayor $\phi$; Fol. 18v: (2 movimiento:) La menor 3/4; Fol. 19v: (3º movimiento:) La Mayor $\not$ - Fol. 20v: [Minué:] La menor 3/4 — Fol. 20v: [Mayor:] La Mayor 2/4. 5) - [Fols. 20v al 23v]. Fol. 20v: Sol menor C [cuarta sección, Vivo]; Fol. 22v: (2 ${ }^{\circ}$ movimiento:) Sol menor 12/8; Fol. 23r: ( $3^{\circ}$ movimiento:) Sol menor C [tres secciones] - Sol menor 3/4. [Tras el fol. 23v numerado a lápiz, y antes del $24 \mathrm{r}$, falta un folio].

6) - [Fols. 24r al 26v]. Fol. 24r: Si menor $\phi$; Fol. 26r: (2 movimiento:) Si menor 6/8. [Fol. 27r y Fol. 27v, en blanco]. [Fol. 28r: «Estas de Escarlati; las podra el S.r D.n Joseph tocar donde gustare» $=K 30, K 41, y K 86]$.

7) - [Fols. 32r al 33v]. Fol. 32r: [encabezamiento:] «Sinfonia J. M. Y J. sean conMigo Amen. Nrã S. ra del Milagro y S. n Antonio». Fa Mayor 3/4; Fol. 32v: (2 movimiento:) Fa Mayor 3/8; Fol. 33r: (3 movimiento:) Fa Mayor C - Fol. 33v: [Minué:] Fa Mayor 3/4.

63. Algunas composiciones editadas, salidas de la producción para tecla de José Nebra Blasco, pueden verse en: -Rosario Álvarez Martínez: Obras inéditas para tecla: José Herrando, Domenico Scarlatti, Francisco Courcelle, José de Nebra y Agustín Massa. Madrid, SEdem, 1984. -Román Escalas: Joseph Nebra (1702-1768). Tocatas y sonata para órgano o clave. Zaragoza, Institución «Fernando el Católico», colección «Tecla Aragonesa, I», 1987. -Ma Salud Álvarez MARTínEZ: Joseph Nebra (1702-1768). Obras inéditas para tecla. Zaragoza, Institución «Fernando el Católico», colección «Tecla Aragonesa, III», 1995. 
8) - [Fols. 33v al 34r]. Fol. 33v: [encabezamiento:] «J M J sean conmigo amen, Nra Sra Del Pilar y S. n Antonio». Do Mayor 2/4; Fol. 34r: (2 movimiento:) «Rondeau»: Do menor 6/8. 9) - [Fols. 34v al 35r]. Fol. 34v: Do Mayor $\phi$; Fol. 35r: ( $2^{\circ}$ movimiento:) «Rondeau»: Do menor 6/8. 10) - [Fol. 35v -último con música-]. Fol. 35v: «inué»: Do Mayor 3/4 [dos secciones]; Fol. 35v: ( $2^{\circ}$ movimiento:) Do menor 3/4. [Explicit: «Obra del S. or D.n Joseph Nebra» - rubricado-].

7) - «Joseph Nebra». «Aria, a dúo», No puedo, que es el cielo. De la zarzuela Viento es la dicha de amor, con libreto de Antonio Zamora, estrenada el 28-XI-1743, por la Compañía de Antonio Palomino.

8) - «Joseph Nebra». «Seguidillas y Fandango», a dúo, Tempestad grande. Del segundo acto de la zarzuela Vendado Amor es, no ziego.

9) - Impreso (41 pp.). Requiem, en Fa Mayor. Escrito para: Coro 1: S 1, 2, A, T; Coro 2: S, A, T, B; vl 1, 2, vla, vlc, cb; fl 1, 2. [Procedente de la Lyra Sacro-Hispana de Hilarión Eslava].

\section{Anónimos atribuidos [José Nebra]}

[10] - Vendado Amor es, no ziego. (Estrenada el 3-VIII-1744, por la Compañía de José Parra). Sin signatura. Partitura completa de la zarzuela, en dos jornadas. Posiblemente se trate de un autógrafo. Un volumen manuscrito, en papel y encuadernado en pergamino, de 156 páginas, más dos sin numerar ${ }^{64}$. A partir del libreto del conocido dramaturgo José de Cañizares $(* 1676 ; \dagger 1747 c)$.

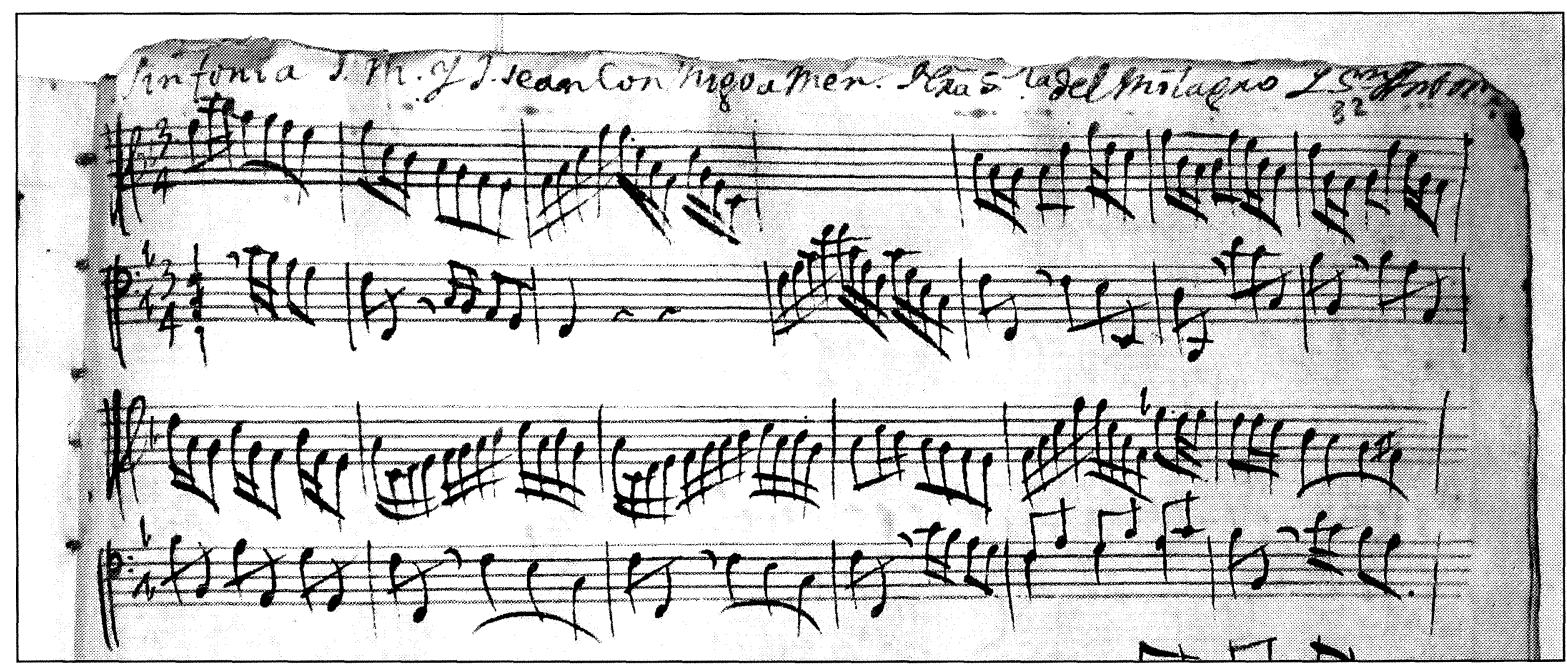

Figura 22

«Vendado Amor es, no Ziego» [atribuida a José Nebra Blasco] Archivo de Música de las Catedrales de Zaragoza [E: Zac, s/s]

64. Sobre esta misma obra, véase: -Luis Antonio GonZÁlez MARín: "Vendado Amor es, no Ziego", en El espejo de nuestra historia. (La diócesis de Zaragoza a través de los siglos). Zaragoza, Edelvives, 1991, p. 324. 
[11] - Zarzuela Donde hay violencia no hay culpa. Con libreto de Nicolás González Martínez. (Estrenada en 1744 por la Compañía de José Parra, en el Coliseo del Duque de Medinaceli). "A la gran deidad de Marte" 6.5

[12] - Loa para el Auto [sacramental] de la Divina Philotea. Silencio, atención, que la culpa y la gracia. Escrita para: S 1, 2, 3, T; vl 1, 2; acompañamiento. Con libreto de Pedro Calderón de la Barca. (Estrenada el 3-VII-1745 por la Compañía de Petronila Jibaja, en el Corral del Príncipe, de Madrid).

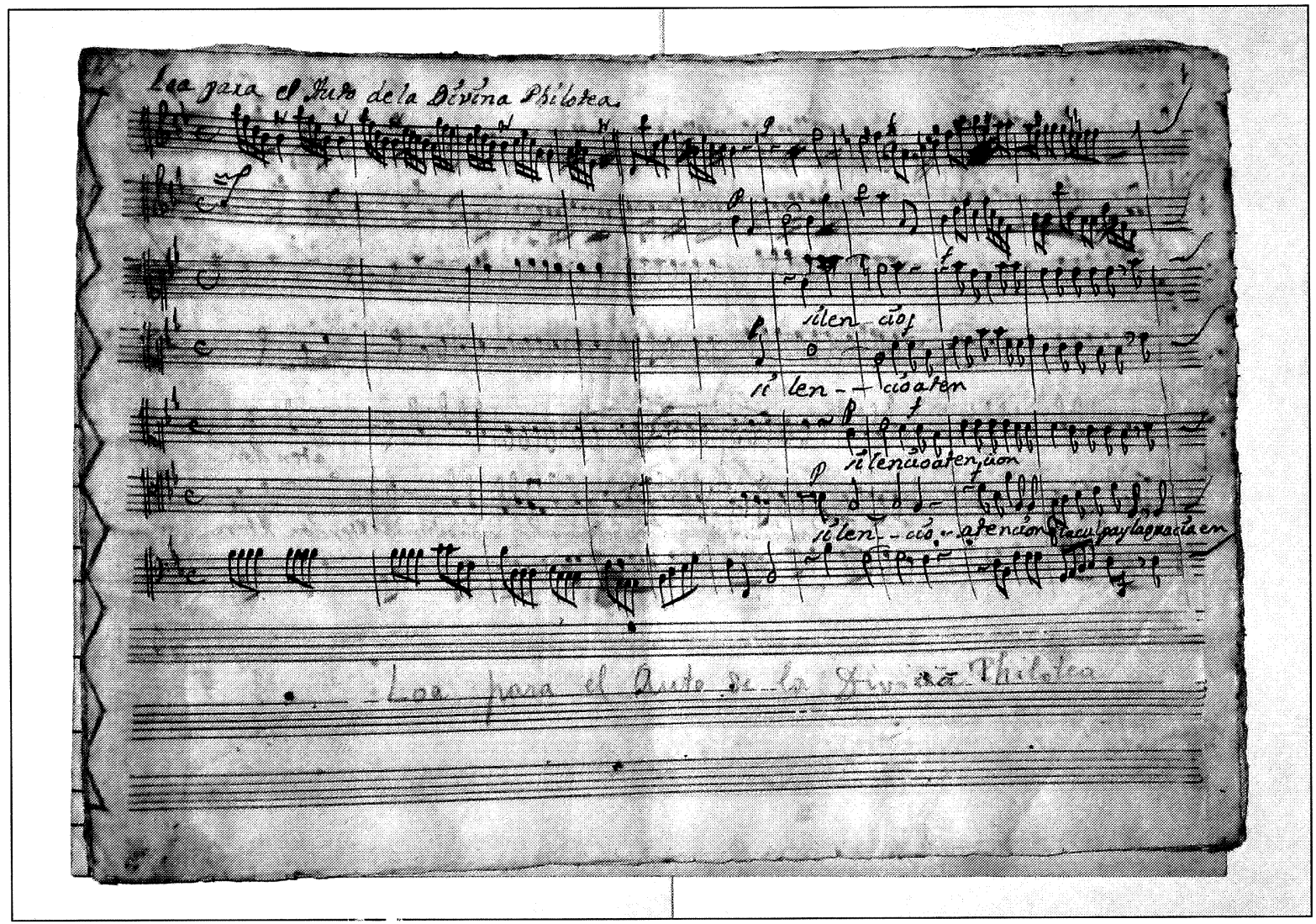

Figura 23

\section{«Loa para el Auto de la Divina Philotea» [atribuida a José Nebra Blasco] Archivo de Música de las Catedrales de Zaragoza [E: Zac, s/s]}

65. Sobre la producción escénica de José Nebra Blasco, véase: -William M. BusseY: "José de Nebra”s «Viento es la dicha de amor»", en French and Italian Influence on the Zarzuela, 1700-1770. Ann Arbor, UMI, 1982, pp. 65-79. -Rainer Leonhard KLEINERTZ: "«Iphigenia en Tracia»: Una zarzuela desconocida de José de Nebra en la biblioteca del Real Monasterio de San Lorenzo del Escorial", en Anuario Musical, 48 (1993), pp. 153-164. - José Máximo Leza: "La zarzuela «Viento es la dicha de amor». Producciones en los teatros públicos madrileños en el siglo xvin", en Música y literatura en la Península Ibérica, 1600-1750. Valladolid, Universidad, 1997, pp. 393-405. - ID.: "Francisco Corradini y la introducción de la ópera en los teatros comerciales de Madrid (1731-1749)", en Artigrama, 12 (1996-1997), pp. 123-146. -Juan José CARRERAS LóPEZ: "From Literes to Nebra: Spanish dramatic Music between tradition and modernity", en Music in Spain during the Eighteenth Century. Cambridge, cup, 1998, pp. 7-16. 
Contamos, por último, con noticia acerca de la actividad de examinadores y evaluadores de instrumentos de teclado de fabricación artesanal local para la Sociedad Económica Aragonesa de Amigos del País en Zaragoza por parte de diversos músicos vinculados a las catedrales de Zaragoza, como el maestro de capilla de La Seo, Francisco Javier García Fajer «el Españoleto», o los organistas Joaquín Laseca y José de Nebra (este último seguramente así citado por error, debiendo referirse a su hermano Joaquín Nebra ${ }^{66}$. Se producen estas actividades en el ámbito de una naciente industria artesanal, que, en el cambio de los siglos XVIII al XIX, pujaba por hallar soluciones alternativas al mercado exterior, por medio de una experimentación y de diversas tentativas organológicas, que se pretendía que fueran económicamente viables. Por su curiosidad e interés, reproduzco esta noticia por extenso a continuación ${ }^{67}$ :

"En el sector industrial y artesano derivado de la madera, la Real Sociedad [Económica Aragonesa de Amigos del País], a través de su clase de artes, siguió una política de protección hacia los artesanos y fabricantes destacados, además de ofrecer unos premios de carácter general para los carpinteros o ebanistas que presentasen obras de línea acabada y al gusto de la época. [...] La separación entre las competencias de los ebanistas y los carpinteros no estaban claras y dieron lugar a numerosos enfrentamientos en los años comprendidos entre 1776 y 1808 . El primer artesano que fue protegido por la Real Sociedad fue Antonio Enríquez, maestro ensamblador residente en Zaragoza, nacido en Villar del Salz en $1747^{68}$, quien en 1778 presentó a la junta general diversos artefactos salidos de su obrador. Eran éstos una trilladora, destrozadora y contorneadora, de la que entregó un diseño, pues la máquina se encontraba en su casa; otra máquina para aventar granos, accionada por dos hombres, cuyo coste no llegaba a las 20 libras jaquesas (358 reales de vellón), y, por último, dos pianofortes de madera de haya, similares a los fabricados en Italia o Inglaterra, cuyo coste era de la mitad que los extranjeros. Estos instrumentos musicales se encontraban funcionando en el convento de Jesús Extramuros de Zaragoza, y se invitaba a la Sociedad a probarlos, pues no se tenía por conveniente transportarlos porque se desafinaban. La Real Sociedad comisionó a Francisco Javier García, maestro de capilla y a José Nebra, organista, ambos de la Seo, quienes tras pulsar los teclados correspondientes manifestaron que estos pianofortes de A. Enríquez eran muy inferiores a los extranjeros. Este informe motivó que se recomendara al constructor que continuase su perfeccionamiento, de manera que un año más tarde, en julio de 1779, volvió a solicitar que se probasen los instrumentos que había mejorado. El conde de Torresecas, asesorado por los peritos de rigor, dictaminó que los pianofortes y los monacordios de A. Enríquez habían sido mejorados sustancialmente y que además su precio se había rebajado con respecto a los anteriores, aunque se sabía por entonces que en Sevilla se hacian estos instrumentos con gran perfección ${ }^{69}$.

66. Sobre este tipo de actividades de los músicos mencionados, véase: -José Francisco ForniÉs CASALs: Fuentes para el estudio de la sociedad y economía aragonesas, 1776-1808. Documentos citados en las Actas de la Real Sociedad Económica Aragonesa de Amigos del País. Zaragoza, Institución «Fernando el Católico», 1980, p. 111. -Antonio EZQUERRO ESTEBAN: "Salamero Reymundo, Francisco: «Ensayo Biográfico sobre Diego Cera, un grausino universal»", [reseña bibliográfica] en Revista de Musicología, XXI/2 (1998), p. 732.

67. Citado en: -José Francisco Forniés Casals: La Real Sociedad Económica Aragonesa de Amigos del País en el periodo de la Ilustración (1776-1808): sus relaciones con el artesanado y la industria. Madrid, Confederación Española de Cajas de Ahorros, 1978, pp. 309-311.

68. Vid.: -Félix de LatasSa y Ortín: Biblioteca Nueva de Escritores Aragoneses. Pamplona, 1799, vol. v, pp. 171-172. 69. El subrayado es mío. Adviértase que este "se sabía por entonces", bien pudiera deberse a Joaquín Nebra, que contaba en Sevilla con buenos familiares músicos (su primo José Blasco, y su sobrino Manuel Blasco), que seguramente actuarían de informadores suyos en este sentido. 
Mas se juzgó oportuno premiarle con 150 reales de vellón y anunciarle en la Gazeta, por ser el primer fabricante de estos instrumentos musicales en Aragón ${ }^{70}$. La relación de la Real Sociedad y A. Enríquez continuó, no en vano era paisano de J. A. Hernández Larrea [Canónigo de La Seo y socio fundador de la Real Sociedad Económica Aragonesa de Amigos del País]. En 1780 volvió a presentar los pianos y los monacordios aún más perfectos, que fueron examinados por el conde de Sástago, Ramón Amat y el conde de Torresecas, quienes le fueron totalmente favorables y elogiaron la labor de taracea que presentaban al exterior ${ }^{71}$. Al siguiente año solicitó que se anunciasen sus instrumentos en la Gazeta; los pianofortes tenían de 6 a 8 palmos de longitud y eran de cuatro tipos: de pino sin color, ni lustre, de nogal con tapa y frentes alustrados, de pino con chapas de nogal y perfiles blancos, y de pino vestido de nogal y perfilado en la misma forma, pero ajustado a la planta de una mesa de tres pies de cabra; los precios de estos modelos, por el mismo orden, eran 600, 1000,1280 y 1600 reales de vellón; en tanto que los monacordios eran de dos tipos: de pino y de nogal y costaban 150 y 225 reales de vellón respectivamente ${ }^{72}$. El interés por los instrumentos musicales no decayó, la relación con A. Enríquez se mantuvo, y años más tarde, en 1796 concretamente, la Económica premió a Tomás Torrente, maestro carretero, por un pianoforte que había construido. El informe de la clase de artes fue muy detallado: el mueble era ligero, elegante, decente y bien decorado, como para estar en cualquier palacio o casa distinguida. La taracea de las maderas era perfecta, los herrajes estaban bien puestos, e iba dotado de solapas para protegerlo del aire y del polvo gracias a su perfecto ajuste. El interior, en virtud de los materiales empleados y del cuidado en su montaje, era muy compacto. El constructor había ideado un sistema fácil de desmontar el teclado, sin peligro de dañar las cuerdas, innovación ésta que no se hallaba en los tratados de construcción de instrumentos musicales contenidos en la Enciclopedia. La dureza del teclado se podía graduar a gusto del comprador, y el sonido era excelente, porque los materiales empleados eran los idóneos. Las pruebas del pianoforte habían sido efectuadas por el presbítero organista mayor de la Seo Joaquín Laseca ${ }^{73}$. Puede, pues, asegurarse que en Zaragoza la construcción de los instrumentos musicales, en especial los pianos y los monacordios, se mejoró considerablemente en el último cuarto del siglo XVIII, con el fin de sustituir los importados y que en este proceso intervino la Real Sociedad con su asesoramiento directo y apoyando a quienes se ocupa-

70. Libros de Resoluciones de la Real Sociedad Económica Aragonesa de Amigos del País; Actas 15-VI-1778, fols. 291-296; 26-VI-1778, fols. 301-309; 15-X-1779, fols. 158-160; y Gazeta de Madrid, 18-1v-1780, p. 270.

71. Nótese que en esta ocasión los peritos examinadores ya no son músicos profesionales a quienes parece quererse evitar; posiblemente pesara en la nueva elección de éstos un intento de eludir la experiencia anterior con músicos (entre ellos, Nebra), la cual no había sido particularmente halagüeña para los intereses comerciales del constructor... Véase ahora cómo, muy posiblemente debido a la escasa competencia musical de los nuevos peritos, lo que se alaba ya no es la calidad intrínsecamente musical de los instrumentos, sino, más bien, "la taracea que presentaban al exterior", es decir, su aspecto físico como muebles u objetos de decoración...

72. Íbid.; Actas 28-I-1780, fols. 19-21; 25-1I-1780, fols. 31-33; 31-III-1780, fols. 39-44; 03-vIII-1781, fols. 129-133; y Gazeta de Madrid, 04-IX-1781, p. 294. Nótese nuevamente, en los carteles anunciadores de los instrumentos, que el aspecto que más se alaba en ellos es su calidad externa de ebanistería, como muebles o meros objetos ornamentales (se habla de las maderas utilizadas, tipos de patas, sus frentes y perfiles...).

73. Íbid.; Actas 13-v-1796, pp. 101-106; 20-v-1796, pp. 106-115; 10-v1-1796, pp. 121-137; y -Diego de Torres: Compendio de las Actas de la Real Sociedad Aragonesa correspondientes al año de 1798, formado mediante comisión de la misma por su Secretario Don Diego de Torres. Zaragoza, Mariano Miedes, 1799, p. 60. [Adviértase que, para esta fecha, Joaquín Nebra, que había sido el examinador de los instrumentos anteriormente (sin duda, debía considerarse al organista de la catedral metropolitana como la mayor autoridad en la materia en el ámbito local), ya había fallecido]. Por otra parte, se conserva también el informe del organista Joaquín Laseca a propósito del pianoforte fabricado por Tomás Torrente (Cfr.: Íbid.; Actas 20-v-1796, pp. 106-115. (Citado en: -José Francisco FonniÉs CASAls: Fuentes para el estudio de la Sociedad y la Economía Aragonesas..., op. cit., 1980, p. 111). Vemos, por tanto, que el sector industrial aragonés de la madera iba a ser favorecido entonces mediante ayudas, con premios y asesoramiento, y que, en este sentido, iba a recibir una especial atención la construcción de instrumentos musicales. 
ban de estas manufacturas, llegando incluso a mejorarse los modelos explicados en la Enciclopedia, compendio éste que era utilizado normalmente por los individuos de la Sociedad como obra de consulta".

A las tentativas de fabricación de instrumentos de teclado antes citadas, todavía cabe añadir un interesante dato:

"Sorprende la rapidez con que este instrumento llega a Zaragoza. En el momento en que Enríquez presenta su primer lote de instrumentos, muchas de las casas inglesas más antiguas están echando a andar. Y ya vemos, por el peritaje de García y de Nebra, que estos instrumentos les son conocidos, pues los comparan con los extranjeros" ${ }^{\text {"74 }}$.
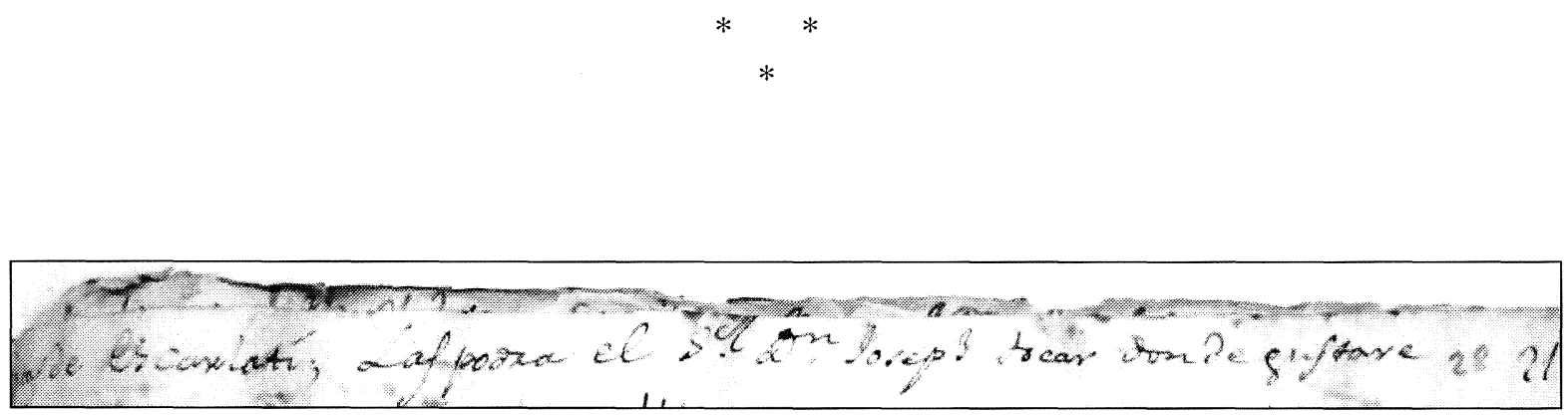

Figura 24.

Sonatas de D. Scarlatti para el uso de José Nebra $(E: Z a c)$.

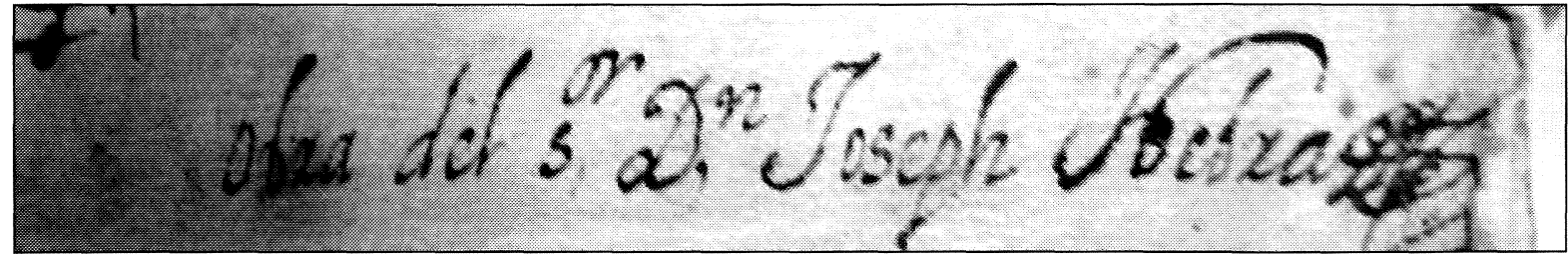

Figura 25.

Autógrafo de José Nebra en la colección de obras para tecla que incluye piezas de D. Scarlatti $(E:$ Zac $)$

74. -Juan José Carreras LóPez: "Pianofortes", en Gran Enciclopedia Aragonesa, Zaragoza, Unali, 1982, tomo x, pp. 2645-2646. 
En definitiva, hemos repasado aquí diversos datos alusivos a la vinculación aragonesa (con Calatayud y Zaragoza) de buena parte de los miembros de la amplia familia de músicos apellidados Nebra. Hemos podido ofrecer documentación de primera mano sobre sus bautizos y confirmaciones cristianas, estableciendo definitivamente la conexión de parentesco entre la rama familiar «Nebra» y la rama de los «Blasco», al tiempo que hemos realizado un rápido seguimiento de las continuas relaciones establecidas entre los diversos miembros de la familia. Paralelamente, a través del análisis de los ejercicios de oposición del joven organista Joaquín Nebra, hemos podido re-situar su nivel personal de competencia técnico-profesional, en el contexto de las exigencias de la época para con un organista profesional activo en el ámbito eclesiástico. Y finalmente, hemos podido comprobar cómo, sobre todo los hermanos Francisco Javier y Joaquín Nebra, llegan a procurarse -incluso desde Roma- ejemplares de la mejor literatura internacional del momento (obras de Händel, de D. Scarlatti, y muy posiblemente también, de Kuhnau y F. Couperin), y cómo son conocedores de los últimos instrumentos de teclado que se están fabricando, tanto en España (Sevilla, Zaragoza), como en el extranjero (Italia, Inglaterra). Una presencia, la de los Nebra en Aragón, por tanto, que dejó una amplia huella, por cuanto abrió, particularmente a los instrumentistas de tecla que vendrían a continuación, nuevos horizontes a cuanto se hacía en el exterior. 